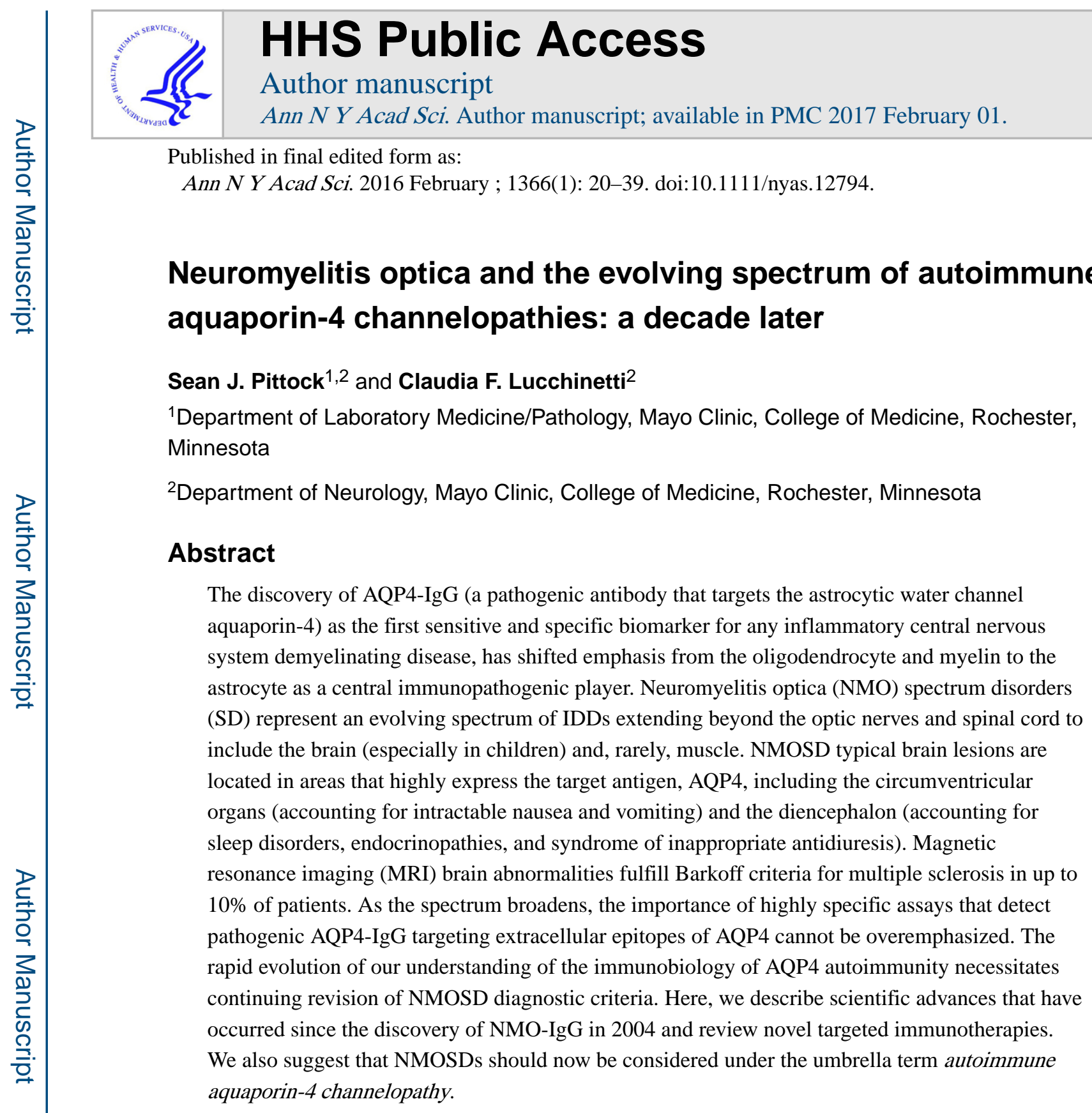

\title{
Keywords
}

aquaporin-4; neuromyelitis optica; multiple sclerosis; optic neuritis; myelitis

\section{Out with the old, in with the new}

In 1894, Devic and Gault reported a case of combined optic neuritis (ON) and myelitis that was fatal and provided a review of 16 similar cases from the literature. ${ }^{1,2}$ The syndrome that Devic described was a monophasic illness characterized by both bilateral optic neuritis and transverse myelitis occurring at the same time. The lack of involvement of the brain was emphasized. ${ }^{3}$ Over the subsequent century, many investigators reported single cases or case

Address for correspondence: Dr. Sean J. Pittock, Mayo Clinic, Department of Neurology, 200 First Street SW, Rochester, MN, 55905. pittock.sean@mayo.edu. 
series of patients with variations on this theme..$^{2-6}$ It became increasingly recognized that patients may have (1) unilateral rather than bilateral optic neuritis, and (2) intervals of weeks to years between attacks of optic neuritis and myelitis rather than simultaneous onset.

Investigators put forward diagnostic criteria for $\mathrm{NMO}$, which emphasized restriction of symptoms and signs to the optic nerves and spinal cord and the requirement of normal brain magnetic resonance imaging (MRI). ${ }^{7}$ Longitudinally extensive T2 signal abnormalities spanning three or more vertebral segments were reported to be characteristic of NMO, a situation rarely found in multiple sclerosis (MS), where lesions (at least in adults) are generally asymmetric and short. Over this period of time, NMO or Devic's syndrome was considered by most to be a variant of MS, and in Asia the disorder was known as opticspinal MS.

In 2004, an autoantibody termed NMO-IgG was reported to be both a sensitive and specific biomarker for NMO (as defined by 1999 Wingerchuk criteria). ${ }^{8}$ Discovery that the target antigen of NMO-IgG was aquaporin (AQP)-4, the most abundant water channel in the central nervous system (CNS), indicated a new direction in CNS demyelinating disease research. ${ }^{9}$ Since then, a combination of clinical, pathological, radiological, and serological observations have clearly distinguished NMO and its partial or inaugural forms (constituting a spectrum of NMO-related disorders, NMOSD) from classical multiple sclerosis, for which no specific biomarkers are recognized. ${ }^{10,11}$ The detection of AQP4-IgG predicts relapses with cumulative attack-related neurological disability, and justifies prompt initiation of immunosuppressive therapy. ${ }^{12-14} \mathrm{AQP} 4$ is highly expressed in astrocytic end feet at the blood-brain barrier, surrounding CNS synapses and nodes of Ranvier, and in areas involved in osmosensitivity and osmoregulation, including supraoptic and paraventricular nuclei of the hypothalamus and circumventricular organs (e.g., the subfornical organ, the organum vasculosum of the lamina terminalis, and the area postrema). ${ }^{10,15,16} \mathrm{AQP} 4$ is also expressed in epithelial cells of the collecting ducts of the kidney, in the parietal cells of the stomach, and in the skeletal muscle. However, these peripheral organs are not usually affected during the course of the disease.

The NMO of today likely represents a different entity from the monophasic disorder originally described by Devic. ${ }^{11}$ This is supported by a significant difference in the prevalence of AQP4-IgG in relapsing ( $>90 \%)$ versus monophasic $(<10 \%)$ disease. ${ }^{11} \mathrm{We}$ suspect that the duration of follow-up may not be long enough to accurately define monophasic in most published reports. This is supported by a single case of AQP4-IgGseropositive monophasic NMO (representing $12.5 \%$ of monophasic cases) reported by Banwell et al. in 2008 who had a relapse subsequent to that publication (unpublished personal communications, Silvia Tenenbaum), thus indicating a $0 \%$ frequency of AQP4-IgG in monophasic pediatric NMO for that study. ${ }^{17}$ The dramatic female preponderance observed in AQP4-IgG seropositive NMO is also not evident in monophasic disease. Furthermore, in the past 60 years, the Mayo Clinic has encountered very few truly monophasic Devic cases with simultaneous optic neuritis and myelitis at onset, but without further attack after adequate follow up ( $>20$ years). 
While a patient may be diagnosed clinically with NMO in the absence of AQP4-IgG positivity, ${ }^{18}$ we consider NMOSD to be defined by the presence of AQP4-IgG. ${ }^{11}$ NMOSDs encompass a broadening clinical spectrum and include NMO but also partial forms, such as longitudinally extensive transverse myelitis (LETM) and recurrent uni- or bilateral optic neuritis (Fig. 1). AQP4-IgG, together with clinical, radiologic, and laboratory findings, unifies a group of discrete, relapsing disorders that are distinct from MS (Table 1).

Here we will provide an overview of what has changed in our understanding of this disease and provide the foundation for a change in how we approach diagnostic criteria moving away from the traditional MS approach, where diagnosis is based on a selection of clinical laboratory and neuroimaging criteria, toward a molecular target-defined approach.

\section{Age, sex, and ethnicity}

NMO incidence and prevalence varies between populations and geographic region. Incidence ranges from 0.053 to 0.40 per 100,000 people. ${ }^{19}$ The prevalence ranges from 0.3 to 4.4 per 100,000. Asian and African-American populations are disproportionately affected, which contrasts with white populations where MS is about 40 times more common than NMO. ${ }^{20-25}$ NMOSD is much more common among women than men (reported ratio ranges from 3:1 to 9:1). ${ }^{26}$ Median age of onset for NMO is 39 years. ${ }^{10,25}$ One in six NMOSD patients are in the pediatric ( $<16$ years) or elderly ( $>65$ years) groups. ${ }^{26}$ There have been no significant genetic risk factors identified for NMO.

\section{The evolving clinical and radiological spectra}

\section{Predilection for optic nerve and spinal cord}

The majority of NMO cases (> 90\%) follow a relapsing course. ${ }^{10,27}$ Relapses of optic neuritis or transverse myelitis usually develop over a period of days and then slowly improve over weeks to months. ${ }^{25,28} \mathrm{NMO}$ attacks tend to be more severe with less recovery than in MS. Disability is generally attack related, unlike MS, where disability mostly occurs as part of the progressive phase of the illness. ${ }^{29-31}$

\section{Optic neuritis}

ON is most frequently unilateral. ${ }^{7}$ In NMOSD, there is a higher propensity for ON to affect more posterior parts of the optic nerve including the chiasm, to have bilateral (simultaneous or sequential) onset, and to be associated with poor visual outcomes. Older studies reported that $60 \%$ of NMO patients experienced unilateral or bilateral blindness at a median of 7.7 years disease duration compared with $4 \%$ in MS ON patients at 15 -year follow-up. 7,32 Optical coherence tomography (OCT) studies have revealed that the retinal nerve fiber layer thinning is greater in NMO patients with ON compared with MS patients. ${ }^{33-36}$ In the AQP4IgG era, outcomes appear more favorable. Jiao et al. reported that at 5 years after disease onset $40 \%$ and $10 \%$ of patients were expected to be blind in one or both eyes, respectively. ${ }^{29}$ 


\section{Transverse myelitis}

MRI of spinal cord in NMOSD demonstrates inflammatory lesions affecting the central gray matter, extending over three or more contiguous vertebral segments. ${ }^{10}$ The length of the lesion depends on the timing of the MRI, because signal abnormality might resolve or become shorter with time. Unlike MS, recovery from attacks is usually incomplete, and patients develop incremental attack-related disability. ${ }^{10}$ Lesions may be spotty with central necrosis and cavitation. Over half of all spinal cord lesions occupy more than half of the spinal cord cross section. ${ }^{37}$ While long lesions are more common, short lesions should not preclude the diagnosis of NMO. A recent study reported that was $14 \%$ of patients present with short lesions on MRI. ${ }^{38}$ Asymptomatic lesions may also be observed. ${ }^{39}$ Painful tonic spasms are also common symptoms and typically occur after a myelitis attack. ${ }^{40}$ Patients also commonly complain of severe neuropathic pain; the most commonly affected areas are the chest, waist, entire length of the legs, or back. ${ }^{41-44}$ In the absence of treatment, approximately $50 \%$ of patients with NMO will be wheelchair dependent and functionally blind and a third will be dead within 5 years after their first attack. ${ }^{7}$ More effective treatments combined with earlier and more accurate diagnosis have led to improved outcomes. Currently, in the AQP4-IgG era, 5 years after onset, less than $28 \%$ of NMO patients require a cane to walk and less than $8 \%$ are wheelchair bound. ${ }^{29}$

\section{Involvement outside optic nerves and spinal cord: argument for moving away from "myelitisoptica" terminology}

Brain lesions are observed in $>60 \%$ of patients. ${ }^{45}$ They are present in over half at symptom onset and increase with disease progression. ${ }^{45-47}$ The majority are non-specific. MS-like brain lesions occur in approximately $10 \%$ of cases, and some fulfill Barkof criteria for MS. ${ }^{45}$ In 2006, an analysis of brain MRI from 120 AQP4-IgG-positive patients described "NMO-typical" brain lesions as being localized at sites of high AQP4 expression at the astroglial foot processes, particularly located in the subpial and subependymal zones around the ventricles. ${ }^{48}$ Diencephalic (thalamic or hypothalamic) lesions may be associated with endocrinopathies, symptomatic forms of narcolepsy, or states of altered consciousness. Hypocretin levels may be reduced in cerebrospinal fluid (CSF).

Extensive cerebral white matter signal abnormalities are sometimes encountered, most commonly in children, and are sometimes associated with encephalopathy. Ito et al. ${ }^{49}$ reported that nearly all enhanced lesions in NMO have a "cloud-like" pattern of enhancement characterized by patchy enhancement with blurred margins. $T_{2}$ hyperintense lesions adjacent to the lateral ventricle and inferior temporal lobe and subcortical U-fiber and Dawson's finger-type lesions are more commonly seen in MS than in NMO. ${ }^{50}$ Magana et al. reported posterior reversible encephalopathy syndrome-like lesions in NMOSD. ${ }^{51}$

Circumventricular organs (CVOs; e.g., area postrema, subfornical organ, organum vascolosum lamina terminalis) are preferentially involved. These specialized structures located along the surface of the brain ventricles are characterized by high AQP4 expression and by the presence of fenestrated capillaries and loosely apposed astrocytic processes. This unique vascular architecture might facilitate the entry of AQP4-IgG. Symptoms and signs attributable to area postrema involvement include intractable hiccups, nausea, and 
vomiting. ${ }^{52,53}$ Intractable hiccups, nausea, and vomiting are the first symptoms in approximately $12 \%$ of NMOSD patients. Dysregulation of osmosensitivity and osmoregulation may lead to syndrome of inappropriate antidiuresis. These symptoms and signs may occur in isolation or in association with the more classical ON or LETM and may herald the onset of NMO. ${ }^{54}$ Skeletal muscle abnormalities characterized by the presence of sarcolemmal immune complex deposition and AQP4 loss were recently reported in an AQP4-IgG-seropositive NMOSD patient ${ }^{55}$ and hyperCKemia was reported in three patients 2 weeks before the onset of NMOSD symptoms. ${ }^{56-60}$ Retinal Müller cells express AQP4 and may be an additional pathogenic target. Recent reports indicate focal retinal vascular attenuation, inner nuclear layer thickening, and microcystic edema in NMO patients. ${ }^{36,61,62}$ Though rare, these findings support the concept that NMOSD may extend beyond the CNS and in some patients be more of a systemic disease.

\section{Pediatric NMO}

Children account for up to $10 \%$ of NMOSD cases. ${ }^{26}$ The disease can affect children as young as 1-2 years of age. Typically, initial manifestations occur between the ages of 10 and 14. The frequency of AQP4-IgG in childhood NMO is similar to that in adults. Furthermore, LETM in children is not as predictive of NMO spectrum disorders as it is in adults. ${ }^{17,63}$ Children tend to have greater brain involvement than adults, and brain lesions are more symptomatic than is typical for adult patients. ${ }^{64} \mathrm{McKeon}$ et al. reported that $45 \%$ of patients had brain attacks with encephalopathy, ophthalmoparesis ataxia, seizures, intractable nausea, and vomiting. Brain MRI abnormalities involved the following areas in decreasing order of frequency: the periventricular white matter, the medulla, the supratentorial and infratentorial white matter, the midbrain, the cerebellum, the thalamus, and the hypothalamus. Of 88 seropositive children, $88 \%$ were girls and the most common ethnicities were African American (34\%), Caucasian (27\%), Hispanic (10\%), and Native American (9\%). ${ }^{64}$

\section{NMO and pregnancy}

There are approximately 100 cases of pregnancy reported in the context of NMO. There is a higher rate of spontaneous abortion in women that are AQP4-IgG seropositive. ${ }^{65}$ In addition, pregnancy negatively affects the outcome for women with NMO. The relapse rate decreases during the first and second trimesters but increases significantly during the third trimester and the first postpartum trimesters. ${ }^{66,67}$ Animal models show high expression of AQP4 in the placenta during the first and second trimester. Intraperitoneal injection of AQP4-IgG into pregnant mice binds to placental AQP4, activates human complement, and induces inflammatory cell infiltration into the placenta with accompanying placental necrosis resulting in fetal death. ${ }^{65}$ Taken together, potential complications must be considered when pregnancy occurs in a woman with NMO.

\section{Detection of AQP4-IgG}

Patients suspected of NMO or NMOSD should have their serum tested for AQP4-IgG. Positivity allows for early distinction between NMO and MS, allowing for faster initiation of therapy appropriate for NMO. AQP4-IgG was initially identified using tissue-based immunofluorescence on mouse composite substrate, given its distinctive binding pattern on 
astrocytic endfeet surrounding the abluminal face of blood vessels, pia, CNS synapses, Virchow-Robin sheaths, and nodes of Ranvier. ${ }^{8}$ Staining of a small subset of kidney cells (collecting duct tubules) is very distinctive and indicative of AQP4-IgG positivity. Subsequent to identification by tissue-based immunofluorescence, immunoprecipitation and ELISA (enzyme-linked immunosorbent assay) assays were developed. However, these assays were prone to false positives and have since been replaced by more sensitive and specific cell-based assays. ${ }^{68,69}$ There are several cell-based assays available that have increased sensitivity without losing disease specificity (97\%). These assays use AQP4transfected cells as a substrate for either immunofluorescence or fluorescence-activated cell sorting (FACS) to detect AQP4-IgG in serum or CSF. Cell-based assays have increased AQP4-IgG-detection rates to almost 90\% compared to 56-68\% with non-cell-based assays..$^{29,30,68-70}$ For many clinical assays, M1 is the preferential isoform used for AQP4$\mathrm{IgG}$ detection owing to increased disease specificity and decreased false positive rate. ${ }^{69} \mathrm{M} 23$ aggregation is thought to increase non-specific binding of IgG molecules. AQP4-IgG testing should be performed before initiation of immunosuppressant therapies (especially high-dose steroids, plasmapheresis, and Rituximab) when possible, as these may result in significant drops in AQP4-IgG titers, sometimes below detection threshold.

\section{NMOSD is commonly associated with organ- and non-organ-specific autoimmunity}

The most commonly encountered coexisting autoimmune conditions with NMOSD include myasthenia gravis, celiac disease, ulcerative colitis, sclerosing cholangitis, systemic lupus erythematosus, rheumatoid arthritis, antiphospholipid antibody syndrome, Sjogren's syndrome, autoimmune hypothyroidism, immune thrombocytopenic purpura, pernicious anemia, pemphigus foliaceus, alopecia areata, psoriasis, scleroderma, dermatitis herpetiformis, polymyositis, chronic inflammatory demyelinating polyneuropathy, paraneoplastic disorders, insulin-dependent diabetes mellitus, and autoimmune encephalitis. ${ }^{71,72}$ Coexisting antibodies in the absence of obvious autoimmune disease are observed in up to $50 \%$ of NMOSD patients and include antinuclear antibodies (43\%), extractable nuclear antigen (15\%), SS-A (10\%), SS-B (3\%), and rheumatoid factor (5\%). ${ }^{73}$ NMOSD patients with coexistent non-organ-specific autoimmunity are reported to have more frequent brain abnormalities than those with AQP4-IgG alone. ${ }^{72}$

There is also a high rate (35\%) of coexisting neural-specific autoantibodies in NMO. Muscle acetylcholine receptor antibody, voltage-gated potassium channel complex antibodies (VGKC, Caspr2, Lgi1) ${ }^{74}$ and collapsin response-mediator protein (CRMP)-5 IgG have all been found in NMOSD. This differs from MS, where there is no significant increase in organ-specific autoimmunity identified. In a study of 88 children with NMOSD, 42\% had coexisting autoimmune disorders. ${ }^{64}$ These findings suggest a genetic predilection for autoimmunity and an amplified humoral immune response. 


\section{NMOSD may be a paraneoplastic disease in some patients with NMOSD, especially the elderly}

A variety of neoplasms have been reported in the context of AQP4-IgG positivity and a clinical diagnosis of NMOSD. These have included breast, lung, thymic, and uterine cervical carcinomas, and ovarian teratoma, B cell lymphoma, thyroid Hürthle cell neoplasm, pituitary somatotropinoma, leiomyosarcoma, and stomach carcinoid. ${ }^{75-79}$ A study focusing on advanced age of onset for NMOSD identified neoplasms in 20\% of AQP4-IgG-seropositive patients over the age of 50 years. ${ }^{80}$ In addition, AQP4-IgG has been found in patients with cancer but lacking NMOSD. Taken together, AQP4-IgG may be a marker of a paraneoplastic immune response in some cases, especially among those greater than 60 years of age.

\section{Cerebrospinal fluid}

CSF pleocytosis with a predominance of neutrophils and eosinophils of 50-1000 $\times 10^{6}$ white blood cells/L and increased protein levels are observed in NMO patients, especially during attacks. ${ }^{10}$ In contrast to MS, oligoclonal bands are found in a minority of AQP4-IgG ${ }^{+}$ NMOSD patients. ${ }^{10}$ NMO patients have increased IL- 6 in their CSF ${ }^{81,82}$ compared to MS and healthy controls, and IL-6 levels correlated with NMO disease severity. IL-6 inhibition appears to prevent attacks in refractory NMO.$^{83,84}$ In an in vitro model, IL-6 signaling promoted AQP4-IgG production from plasmablasts and blockade of the IL-6 receptor reduced survival of the plasmablasts. CSF glial fibrillary acidic protein (GFAP) levels are reported to be several thousand times higher than in MS and can be a distinguishing feature. ${ }^{85-87}$

\section{Immunopathological outcome of AQP4-IgG binding to its target antigen}

\section{Aquaporin-4: structure, function, expression}

$\mathrm{AQP} 4$, the most abundant water channel in the CNS, has a polarized expression and is enriched on astrocytic endfeet at fluid-parenchymal interfaces. ${ }^{15,16} \mathrm{AQP} 4$ is known to facilitate water flux in the brain and spinal cord during normal synaptic transmission, following injury, and during cell migration. ${ }^{88}$ Mice lacking AQP4 have better outcomes in models of cytotoxic edema (cellular swelling induced by water intoxication and ischemia ${ }^{89}$ ) and poorer outcomes in models of vasogenic edema (water accumulating in extracellular spaces such as during breakdown of the blood-brain barrier ${ }^{90}$ ), a common symptom associated with brain tumors, abscesses, and hemorrhage. AQP4 has also been shown to be important for neuroexcitation and reuptake of glutamate after synaptic transmission.

In addition to the CNS, AQP4 is also expressed in many non-neural tissues including skeletal muscle (fast-twitch fibers), stomach (parietal cells), lung airway cells, kidney (collecting duct cells), inner ear (Claudius, Hensen, and inner sulcus cells), eye (retinal Müller cells and lacrimal gland), salivary glands (duct cells), and olfactory epithelial cells. ${ }^{91}$ The varied expression of the autoantigen is reflected in the diverse phenotypes characterizing NMOSD. Rare subtle yet significant physiologic effects of AQP4-IgG binding to AQP4 in non-neural tissues have been reported. For example, skeletal muscle abnormalities were recently reported in an AQP4-IgG-seropositive NMOSD patient ${ }^{55}$ and 
hyperCKemia was reported in three patients two weeks before the onset of NMOSD symptoms. ${ }^{56-60}$ It is unclear why AQP4-IgG primarily causes CNS lesions by activating complement, but generally spares peripheral AQP4-expressing organs. A recent study demonstrated that in normal brain, astrocyte endfeet express AQP4, but are devoid of complement regulatory proteins CD46, CD55, and CD59. ${ }^{92} \mathrm{AQP} 4$ is coexpressed with CD59 in astrocytes cultured alone, but in astrocyte-endothelial co-cultures, coexpression of CD59 is absent. This suggests that astrocytes co-cultured with endothelial cells (as would be the case in vivo) are more vulnerable to AQP4-IgG and complement-mediated lysis than astrocytes cultured alone. These findings may explain why NMO primarily damages the CNS but spares peripheral organs. In the kidney, AQP4 is coexpressed with CD46 and CD55; in stomach, with CD46; and in skeletal muscle, with CD46. Complement regulators protect peripheral organs, but not the CNS, from AQP4-IgG- and complement-mediated damage. It will be of interest to investigate complement regulatory protein expression in patients with involvement of extra CNS tissues.

There are two predominant AQP4 isoforms (M1 and M23), and they interact with themselves and each other to form homo- and heterotetramers. ${ }^{90,93}$ Each AQP4 monomer contains six membrane-spanning domains surrounding a central pore. M1 and M23 differ at the cytoplasmic N-terminus, which in M1 has 22 additional residues. ${ }^{94-96}$ M23 homotetramers assemble into higher-order structures, called orthogonal arrays of particles (OAPs), which are an ultrastructural hallmark of astrocytic endfeet membranes. 9798 Bordering heterotetramers containing M1 and M23 limit OAP size, owing to interactions with the first 22 residues in the longer M1 N-terminus interacting with $\mathrm{N}$-terminal residues of M23 that are essential for M23 homotetramerization. ${ }^{99}$ It was proposed that AQP4-IgG only binds to AQP4-M23, ${ }^{100}$ but it is now well documented that AQP4-IgG binds to both M1 and M23, which have identical extracellular domains. ${ }^{9,69,101}$

\section{Molecular outcome of IgG binding to AQP4: in vitro studies}

AQP4-IgG is a polyclonal autoantibody that binds multiple epitopes with variable avidity for both AQP4-M1 and AQP4-M23. ${ }^{101}$ Effects of AQP4-IgG binding to AQP4 are diverse and isoform specific (Fig. 2). After binding of IgGs to AQP4, there is preferential internalization of the M1 isoform and reorganization and aggregation of M23 rather than internalization. ${ }^{102,103}$ Loss of AQP4 through internalization decreases water transport. ${ }^{103}$ Internalization of AQP4 (and associated EAAT2) is thought to be through cross-linking by AQP4-IgG, which induces aggregation of surface AQP4. Cross-linked proteins on the membrane initiate a series of signaling cascades resulting in endocytosis of that portion of the membrane. Large aggregates are more resistant to endocytosis and remain on the membrane, accessible for complement-mediated cellular cytotoxicity (CDCC). Regions with a higher proportion of $\mathrm{M} 1$ would be internalized more rapidly and less available to $\mathrm{CDCC}$, perhaps sparing that area from destructive damage. AQP4-M1 is rapidly replaced on the plasma membrane after removal of AQP4-IgG. ${ }^{102}$ This may be a model mimicking reversible lesions after antibody-depleting therapies. In contrast, areas rich in AQP4-M23 would be more prone to CDCC, and these regions may reflect the more necrotic lesions. Individual variations in AQP4-M1 and AQP4-M23 expression profiles conceivably could contribute to the variability seen in NMOSD lesions. 
Expression of the glutamate transporter EAAT2 (excitatory amino acid transporter 2) is also decreased after AQP4-IgG binding to AQP4, with a concomitant decrease in glutamate uptake. ${ }^{104,105}$ EAAT2 and AQP4 reside in a common complex in astrocyte membranes and are functionally coupled. ${ }^{106}$ Uptake, recycling, and degradation of neurotransmitters from the synaptic cleft after synaptic transmission is a vital function of astrocytes. ${ }^{107}$ EAAT1 and EAAT2 expressed on astrocyte membranes are responsible for efficient removal of extracellular glutamate after synaptic activity in the brain. ${ }^{108}$ While astrocytes are more resistant to damage caused by excess extracellular glutamate, loss of EAAT2 in NMO lesions is thought to contribute to excitotoxic death of oligodendrocytes and subsequent demyelination, even in the context of GFAP preservation in some NMOSD lesions.

Howe and colleagues recently demonstrated a robust pattern of gene expression changes consistent with the induction of a reactive and inflammatory phenotype in primary rat astrocyte-enriched cultures after treatment with NMO patient-derived serum or purified IgG. ${ }^{109}$ Interaction of AQP4-IgG with its astrocytic target resulted in a 50-fold upregulation of $L c n 2$, consistent with a reactive astrocyte phenotype. They also observed upregulation of genes encoding adhesion factors (ICAM-1 and VCAM-1), the initiation of oxidative stress response pathways involving SOD2, ceruloplasmin, and NF- $\mathrm{kB}$, and the upregulation of inflammasome components (caspase-1 and various proteasome subunits). AQP4-IgG induced a greater than fivefold upregulation of IL- $1 \alpha$ and IL-1 $\beta$, and a greater than twofold increase in IL-6, IL-10, and IL-33. The pattern of chemokine induction was heavily skewed toward monocytic (CCL2/3/4/5/7/12 on CCR2), neutrophilic (CXCL1/2/6 on CXCR1/2), and eosinophilic (CCL5/7 on CCR3) recruitment. These data provide in vitro support to the immunopathologic findings demonstrating eosinophils and neutrophils in NMO lesions ${ }^{110}$ and the recent correlation between CSF levels of the human CXCR2 ligand CXCL8 (functionally homologous to CXCL1/2 in rodents) with disability score in NMO patients. ${ }^{111}$ Saadoun et al. also showed a protective effect of neutropenia and increased pathology by neutrophilia in their rat model of intracerebral injection of AQP4-IgG with human complement. ${ }^{112}$ In addition, within hours of AQP4-IgG binding to astrocytes in culture, there was a robust production of $\mathrm{C} 1 \mathrm{q}$, the initator of the classical complement cascade. In the quiescent nervous system, $\mathrm{C} 1 \mathrm{q}$ is absent. ${ }^{113}$ The early recruitment of granulocytes into NMO lesions likely precedes classical complement activation and antibody-dependent cellular cytotoxicity (ADCC). ${ }^{110,114}$ Therefore, targeting this astrocytic inflammatory response could be a fruitful strategy for attenuating NMOSD severity.

\section{Lacking a good animal model of NMO}

Many groups have attempted to develop an animal model that mimics the human disease. ${ }^{115}$ Traditional methods for developing animal models of immunoglobulin-mediated diseases, such as passive transfer of human IgG or active immunization with recombinant protein, have been unsuccessful in eliciting signs reminiscent of NMOSD. Minimal success has been achieved by injecting AQP4-IgG with human complement directly into the brains of rodents ${ }^{112,116,117}$ or passively transferring AQP4-IgG into animals that already have a compromised blood-brain barrier such as those used in models of MS (experimental autoimmune encephalitis (EAE)) as the background strain. ${ }^{118-121}$ Direct injection of AQP4IgG with human complement produces pathology reminiscent of the human disease, with 
AQP4 loss, granulocyte infiltration, complement deposition, and axonal injury. EAE models produce similar symptoms, but neither model is a true reflection of human NMOSD. The lack of a robust model has forced researchers to study the effects of AQP4-IgG in vitro using cell culture and spinal cord slice cultures. While these systems have provided broad insight into the pathogenic mechanisms of AQP4-IgG, animal models would greatly increase our knowledge of NMOSD, leading to better understanding of disease initiation, progression, and therapeutics.

\section{Immunopathological characteristics support in vitro and in vivo experimental data}

Histopathologically, there are two types of NMOSD lesions. ${ }^{115}$ The classic acute lesion is characterized by confluent and/or perivascular demyelination, macrophage infiltration, and axonal and astrocyte loss with necrosis of both gray and white matter of the spinal cord. The second type is characterized by vacuolated myelin in the absence of obvious demyelination, reactive astrocytes, microglial activation, and granulocyte inflammation with minimal axonal injury. ${ }^{103,114,122}$ These non-demyelinated lesions do not necessarily progress to necrotic lesions and may be reversible. Before the identification of AQP4-IgG, evidence of humoral mechanisms of pathogenicity was reported in NMO lesions; ${ }^{110} 82$ lesions from nine autopsy cases revealed extensive demyelination at multiple spinal cord levels, cavitation, necrosis, and acute axonal pathology in both gray and white matter. Oligodendrocyte loss was a prominent feature, with infiltrates of inflammatory cells such as macrophages, perivascular granulocytes, eosinophils, and variable numbers of T cells. Pronounced vascular deposition of immunoglobulins and complement $\mathrm{C} 9$ neo antigen were present in active demyelinated lesions with fibrosis and hyalinization of blood vessels. These features are distinct from MS, where vasculocentric complement deposition, eosinophil infiltration, and vascular fibrosis are not typical.

After the discovery of AQP4-IgG, Roemer et al, demonstrated marked loss of AQP4 independent of stage of demyelination, tissue necrosis, or site of CNS involvement. ${ }^{122}$ Loss of AQP4 was observed in the absence of demyelination or necrosis, indicating that loss of AQP4 is not simply due to astrocyte loss. Area postrema lesions were characterized by tissue rarefaction, thickening of the blood vessels, and myelin preservation in the subependymal medullary tegmentum. Neuronal and axonal pathology was not obvious. ${ }^{123}$ Similar to spinal cord lesions, AQP4 loss is frequently pronounced in area postrema lesions with lymphocytic inflammatory cells, microglial activation, and, sometimes, eosinophilic infiltrates.

Complement deposition and astrocyte activation is also present. ${ }^{123} \mathrm{NMO}$ lesions contain IgG-specific plasma cells ${ }^{102}$ and, consistent with in vitro data, may show loss of the glutamate transporter EAAT2. ${ }^{115}$

A recent study revealed that $\mathrm{AQP} 4$ immunohistochemistry was helpful in differentiating NMO/NMOSD from MS among a surgical biopsy cohort of 19 patients with tumefactive active demyelinating lesions. Those patients demonstrating pathological evidence for AQP4 loss in regions of active demyelination were subsequently shown to either be seropositive for NMO-IgG or had a diagnosis consistent with NMO/NMOSD, whereas patients with 
increased AQP4 expression were later confirmed to have MS. ${ }^{124}$ This study also revealed that seven of the $17 \mathrm{NMO} / \mathrm{NMOSD}$ patients presented with tumefactive brain lesions prompting brain biopsy. The recognition that NMOSD may present as a mass brain lesion should prompt serological testing for AQP4-IgG, which may help avert a brain biopsy.

AQP4 is also expressed in normal cortex, and cortical gray matter abnormalities have been described on MRI. ${ }^{125,126}$ Cortical changes in NMO include promonent gliosis, scattered pyknotic neurons, and loss of AQP4 in cortical layer 1, but no evidence of cortical demyelination. 127

A broad spectrum of astrocytic pathology has been described in NMO lesions including the presence of astrocyte loss, dystrophic astrocytic profiles, astrocyte mitoses, multinucleated astrocytes, and bipolar progenitor astrocytes. The extent of observed pathological changes in astrocytes is distinct from MS, and underscores that in the CNS, NMO is a primary astrocytopathy. ${ }^{115}$

\section{Therapeutic approach}

\section{Acute attack}

The first line of treatment in the management of an acute attack is intravenous corticosteroids. The usual dose given is $1000 \mathrm{mg}$ of methylprednisolone intravenously daily for 5 consecutive days. This approach is mainly supported from case series or by extrapolation from clinical trials involving patients with single-episode ON or MS. In our experience, early treatment is best. Patients with NMOSD who present with subtle symptoms suggestive of an early potential attack (e.g., new-onset back pain or tingling numbness in the legs) should alert the clinician to consider prompt initiation of intravenous methylprednisolone or high-dose oral prednisone, given the potential for rapid progression and severe attack-related disability. In cases where patients have developed disability and have not responded to intravenous methylprednisolone, there is good data from both prospective and retrospective studies to support the use of plasma exchange (i.e., plasmapheresis, approximately 1.5 plasma volume every other day for five to seven treatments) as a second line of treatment. A recent study reported that intravenous immune globulin may also have a role in treating acute NMO relapses.

\section{Attack prevention}

Disability in NMO is attack related. Thus, it would be expected that attack prevention through early commencement of immunotherapy will have a much greater impact on longterm disability for NMOSD compared with MS. Currently, immunosuppression is the mainstay of treatment in NMO (Table 2). On the basis of relatively small retrospective and open-label prospective series, several treatments appear to be effective in preventing attacks and stabilizing disability in NMO. These studies, unfortunately, are limited by lack of randomization. Given the rarity of NMO, future randomized controlled studies will require participation of multiple centers. Despite the inherent limitations of such studies, treatments appear moderately or highly effective and, thus, placebo-controlled trials in this disease will likely be considered unethical by most. Cost, availability, patient choice, route of 
administration, side effects, and physician familiarity with immunosuppressant medications will likely influence therapeutic decision making. Breakthrough attacks should result in reevaluation of treatment strategy. Reasons for treatment failure may include suboptimal dosage, inadequate duration of treatment, and the potential development of neutralizing antibodies in the case of monoclonal antibody therapies.

Future therapies for the treatment of NMO are aimed at several pathways involved in disease pathogenesis, and many of these hold promise for potential monotherapies or as a multifaceted combined therapeutic approach. For patients with previous debilitating spinal cord or optic nerve damage, transplantation of neural and glial stem cells may provide some hope for regeneration in the future.

\section{Novel investigational immunotherapies and repurposing}

Advanced serological interpretive insights, coupled with increased understanding of the pathogenic impact of binding of NMO-IgG to AQP4 on the astrocytic endfoot, have led to the discovery of novel therapeutic targets (Fig. 2). These discoveries open up possibilities for repurposing of drugs already available, as well as the potential development of NMOspecific therapies. ${ }^{128}$

Complement inhibition-Complement activation after binding of AQP4-IgG to its target is a major determinant of CNS inflammation and astrocytic injury in NMO. Eculizumab is a therapeutic humanized monoclonal $\mathrm{IgG}$ that neutralizes the complement protein $\mathrm{C} 5$, thereby inhibiting its cleavage to $\mathrm{C} 5 \mathrm{a}$ and $\mathrm{C} 5 \mathrm{~b}$, which prevents generation of the proinflammatory and cell-activating C5a peptide, the lytic terminal complex C5b-9, and the non-cytolytic soluble C5b-9 inflammatory product. A recent open-label treatment trial showed promise, and a randomized, double-blind, placebo-controlled, multi-center trial to evaluate the safety and efficacy of eculizumab in patients with relapsing NMO is currently enrolling patients. ${ }^{129}$

C1-targeted monoclonal antibodies have also been shown to reduce AQP4 antibodymediated injury in in vitro and in vivo models of NMO. Another potential target in NMO is CD59. This is a major complement inhibitory protein in astrocytes. Pharmacological upregulation of this protein or other complement inhibitors may be beneficial in reducing AQP4-IgG-dependent cytotoxic complement-dependent toxicity.

IL-6 receptor-targeted therapy-Recent data indicates that plasmablasts, a $\mathrm{CD} 19^{\text {int }} \mathrm{CD} 20^{-} \mathrm{CD} 27^{+} \mathrm{CD} 38^{+} \mathrm{B}$ cell subset, are the primary source of AQP4-IgG production. ${ }^{130}$ Since this population of cells is $\mathrm{CD} 20^{-}$, they would not be affected by rituximab and may explain why some patients continue to have relapses despite rituximab therapy. Plasmablast survival is dependent on IL-6. CSF, IL-6, and soluble IL-6 receptor levels are increased at the time of an NMO attack, and the plasmablast population also increases during a NMO relapse. Tocilizumab, an IL-6 receptor-blocking antibody, decreases AQP4-IgG production and reduces the numbers of circulating plasmablasts. ${ }^{131}$ Several case reports have shown that monthly infusion of this medication is beneficial in refractory NMO ${ }^{83,84,131}$ Another anti-IL-6 receptor monoclonal antibody, SA237, with greater duration of action than Tocilizumab, has recently entered a phase III clinical trial. 
Anti-CD19-targeted therapy-Plasmablasts are increased in the CSF and peripheral blood at time of an NMO relapse. ${ }^{18130}$ All CD20 ${ }^{+}$cells express CD19, but not all CD19+ cells express $\mathrm{CD} 20{ }^{132}$ Given the evidence that there is a unique role for $\mathrm{CD} 19^{+} \mathrm{CD} 20^{-}$ plasmablasts in the pathogenesis of NMO, it is postulated that anti-CD19-mediated B cell depletion may, in fact, be more beneficial than rituximab and provide additional options for physicians and patients. Several CD19-targeted therapies are currently under active investigation, ${ }^{133}$ and a humanized ADCC-enhanced affinity-optimized immunoglobulin-G1 monoclonal antibody targeting CD19 is currently entering a phase III randomized control trial in NMO.

Blockade of AQP4-IgG binding to AQP4-A non-pathogenic human monoclonal antibody, aquaporimab, generated from a recombinant monoclonal AQP4-IgG, with a mutated Fc receptor abolishing its ability to activate complement or generate antibodydependent cellular cytotoxicity, is currently in preclinical development. ${ }^{134}$ Aquaporumab, in vitro, competitively blocks or dislodges AQP4-IgG, preventing its binding and pathogenic effector functions, thus reducing AQP4-IgG-dependent astrocytic injury.

Granulocyte-targeted therapies-In mouse models of NMO and in mouse spinal cord slices, elimination or inhibition of neutrophils reduces tissue damage whereas increased neutrophil counts exacerbate tissue damage. Sivelestat, a small molecule inhibitor of neutrophil elastase, has been shown to reduce NMO pathology in a mouse model of NMO. Currently, Sivelestat is being investigated in a small clinical trial in Japan as a treatment for acute NMO attacks. ${ }^{112}$

Eosinophil-targeted therapies-Immunopathologic studies have reported a preponderance of eosinophils in the acute NMO lesion. Eosinophils cultured from mouse BM produce AQP4-IgG-dependent ADCC in AQP4-expressing cells and spinal cord slice cultures. In the presence of complement, eosinophils produced complement-dependent cellular cytotoxicity. Antihistamines, cetirizine and ketotifen have been shown to reduce cytotoxicity mediated by AQP4-IgG and eosinophils in these models. Eosinophil-stabilizing agents are currently being studied in small numbers of patients with NMO. ${ }^{128}$

Diagnostic criteria: looking to the future-a new nomenclature required-In 2006, Wingerchuk and colleagues at the Mayo Clinic proposed that a diagnosis of NMO requires simultaneous $\mathrm{ON}$ and acute myelitis together with one of the following additional criteria: a contiguous spinal cord MRI lesion spanning three vertebral segments in length or greater or a brain MRI not meeting diagnostic criteria for MS or AQP4-IgG positivity. ${ }^{18}$ The explosion in clinical and basic science research driven by the AQP4-IgG biomarker has dramatically expanded the clinical and neuroimaging spectrum of NMO, rendering the 2006 criteria inadequate for clinical diagnosis. The recognition that AQP4-IgG-seropositive patients may have limited or inaugural forms of NMO such as a first attack of LETM or ON or cerebral, diencephalic, or brain stem lesions resulted in the introduction of the term "NMO spectrum disorders" (NMOSD) in 2006. ${ }^{18}$ From a practical perspective, this would allow a patient with a single episode of $\mathrm{ON}$ or transverse myelitis, or intractable vomiting and seropositivity for AQP4-IgG, to obtain a diagnosis before a second event and allow early 
initiation of immunosuppression. This is supported by recent studies reporting that seropositivity for AQP4-IgG in such clinically isolated syndromes is highly predictive of further relapses. ${ }^{12-14,53}$ Immunopathologic studies confirmed that NMO lesion pathology in the brain matches that of the spinal cord and is distinct from that of MS. ${ }^{115}$ Recent reports have indicated that muscle and retinal AQP4 may be targeted. ${ }^{52,53,55-62,110}$

These diverse disorders are unified by a specific biomarker, and since many of the symptoms and signs extend beyond the spinal cord (myelitis) and optic nerves (optica), we suggest a new terminology consistent with the evolving nomenclature used in autoimmune neurological diseases that is molecular target defined. The term autoimmune AQP4 channelopathy is inclusive of the expanding systemic phenotype thus far identified and is represented in the schema proposed in Figure 1, where the core diagnostic criterion is the presence of the AQP4-IgG biomarker (and assumes no false positivity). The absence of AQP4-IgG might indicate an alternative diagnosis, such as MS, another demyelinating disorder, or an indeterminate diagnosis. Similarly, the term autoimmune NMDAR encephalitis has been used to define the encephalopathy resulting from targeted attack of the NMDAR by pathogenic IgGs. ${ }^{135,136}$

The IgG specific for myelin oligodendrocyte glycoprotein (MOG), a minor component of CNS myelin, has been reproducibly reported in 10-15\% of AQP4-IgG-seronegative patients with NMO phenotype..$^{70,137-140}$ Using cell-based assays expressing recombinant MOG, rather than earlier-generation assays employing denatured MOG protein (western blot/ ELISA), MS patients' sera are consistently negative. Unlike AQP4-IgG-seropositive patients with NMO spectrum disorders, MOG-IgG-seropositive patients are commonly male, younger at the onset of transverse myelitis or $\mathrm{ON}$, and may have conus and deep gray matter involvement and more favorable outcome. MRI abnormalities in MOG-IgG-seropositive patients appear to resolve more completely following immunotherapy than in AQP4-IgGseropositive patients. Additionally, symptoms and signs in MOG-IgG-seropositive cases tend to involve the optic nerve more than the spinal cord, are more frequently simultaneously bilateral, and are more likely to be monophasic in course. The pathogenicity of MOG-IgG is yet to be determined. Thus, the evolving spectrum of inflammatory CNS disorders defined by MOG antibodies will likely extend beyond an NMO-like phenotype to include acute disseminated encephalomyelitis (ADEM) and other MS-mimic diseases, warranting the new term autoimmune MOG oligodendrocytopathy or MOG-opathy. ${ }^{141}$ Such an approach to classification of inflammatory CNS demyelinating diseases where the molecular target is known (Fig. 3) recognizes that clinical phenotype may be shared (for example optic neuritis or transverse myelitis) though the immunopathogenic mechanisms may differ (astrocytopathy in AQP4 autoimmunity and oligodendrogliopathy in MOG autoimmunity. Recognition of such immunopathogenic differences will likely be important as more individualized and mechanistically targeted therapies become available.

\section{Acknowledgments}

Dr. Pittock and the Mayo Clinic have a financial interest in patents (\#12/678,350 filed 2010 and \#12/573,942 filed 2008) that relate to functional AQP4/NMO-IgG assays and NMO-IgG as a cancer marker; Dr. Pittock has provided consultation to Alexion Pharmaceuticals, Medimmune, and Chugai Pharma USA but has received no personal fees or personal compensation for these consulting activities. All compensation for consulting activities is paid directly 
to Mayo Clinic. Dr. Pittock has received a research grant from Alexion Pharmaceuticals for an investigator-initiated study, as well as support from the NIH (RO1 NS065829-01) and the Guthy Jackson Charitable Foundation for NMO research.

Dr. Lucchinetti serves on scientific advisory boards for the NIH/NINDS CNBT Study Section. She has received funding for travel or speaker honoraria from Biogen Idec. Dr. Lucchinetti serves on the editorial board for Brain Pathology. She has a patent and received royalty payments regarding aquaporin-4-associated antibodies for diagnosis of neuromyelitis optica. Dr. Lucchinetti has publishing royalties for the Blue Books of Neurology: Multiple Sclerosis 3 (Saunders Elsevier, 2010). Dr. Lucchinetti is a consultant for Biogen Idec and QuestCor. She receives research support form Novartis, the NIH, the Department of Defense, the National Multiple Sclerosis Society, and the Guthy Jackson Charitable Foundation.

\section{References}

1. Devic E. Myélite aiguë dorso-lombaire avec névrite optique. - Autopsie. Congres francais de medecine. 1895:434-439.

2. Gault F. De la neuromyelite optique aigue. These: Faculte de Medecine et de Pharmacie. 1894

3. Jarius S, Wildemann B. The history of neuromyelitis optica. J Neuroinflammation. 2013; 10:8. [PubMed: 23320783]

4. Jarius S, Wildemann B. An early case of neuromyelitis optica: on a forgotten report by Jacob Lockhart Clarke, FRS. Mult Scler. 2011; 17(11):1384-1386. [PubMed: 21690148]

5. Jarius S, Wildemann B. The case of the Marquis de Causan (1804): an early account of visual loss associated with spinal cord inflammation. J Neurol. 2012; 259(7):1354-1357. [PubMed: 22237820]

6. Jarius S, Wildemann B. 'Noteomielite' accompanied by acute amaurosis (1844). An early case of neuromyelitis optica. J Neurol Sci. 2012; 313(1-2):182-184. [PubMed: 21992815]

7. Wingerchuk DM, Hogancamp WF, O'Brien PC, Weinshenker BG. The clinical course of neuromyelitis optica (Devic's syndrome). Neurology. 1999; 53(5):1107-1114. [PubMed: 10496275]

8. Lennon VA, Wingerchuk DM, Kryzer TJ, Pittock SJ, Lucchinetti CF, Fujihara K, et al. A serum autoantibody marker of neuromyelitis optica: distinction from multiple sclerosis. Lancet. 2004; 364(9451):2106-2112. [PubMed: 15589308]

9. Lennon VA, Kryzer TJ, Pittock SJ, Verkman AS, Hinson SR. IgG marker of optic-spinal multiple sclerosis binds to the aquaporin-4 water channel. J Exp Med. 2005; 202(4):473-477. [PubMed: 16087714]

10. Wingerchuk DM, Lennon VA, Lucchinetti CF, Pittock SJ, Weinshenker BG. The spectrum of neuromyelitis optica. Lancet Neurol. 2007; 6(9):805-815. [PubMed: 17706564]

11. Iorio R, Pittock SJ. Neuromyelitis optica and the evolving spectrum of autoimmune aquaporin-4 channelopathies. Clinical and Experimental Neuroimmunology. 2014; 5(2):175-187.

12. Weinshenker BG, Wingerchuk DM, Vukusic S, Linbo L, Pittock SJ, Lucchinetti CF, et al. Neuromyelitis optica IgG predicts relapse after longitudinally extensive transverse myelitis. Ann Neurol. 2006; 59(3):566-569. [PubMed: 16453327]

13. Jarius S, Frederikson J, Waters P, Paul F, Akman-Demir G, Marignier R, et al. Frequency and prognostic impact of antibodies to aquaporin-4 in patients with optic neuritis. J Neurol Sci. 2010; 298(1-2):158-162. [PubMed: 20850793]

14. Etemadifar M, Abtahi MA, Razmjoo H, Abtahi SH, Dehghani AR, Abtahi ZA, et al. Antiaquaporin-4 IgG in Patients Presenting with Unilateral Optic Neuritis: A Cohort Study. Int J Prev Med. 2012; 3(9):612-615. [PubMed: 23024849]

15. Nielsen S, Nagelhus EA, Amiry-Moghaddam M, Bourque C, Agre P, Ottersen OP. Specialized membrane domains for water transport in glial cells: high-resolution immunogold cytochemistry of aquaporin-4 in rat brain. J Neurosci. 1997; 17(1):171-180. [PubMed: 8987746]

16. Rash JE, Yasumura T, Hudson CS, Agre P, Nielsen S. Direct immunogold labeling of aquaporin-4 in square arrays of astrocyte and ependymocyte plasma membranes in rat brain and spinal cord. Proc Natl Acad Sci U S A. 1998; 95(20):11981-11986. [PubMed: 9751776]

17. Banwell B, Tenembaum S, Lennon VA, Ursell E, Kennedy J, Bar-Or A, et al. Neuromyelitis optica-IgG in childhood inflammatory demyelinating CNS disorders. Neurology. 2008; 70(5):344352. [PubMed: 18094334] 
18. Wingerchuk DM, Lennon VA, Pittock SJ, Lucchinetti CF, Weinshenker BG. Revised diagnostic criteria for neuromyelitis optica. Neurology. 2006; 66(10):1485-1489. [PubMed: 16717206]

19. Marrie RA, Gryba C. The incidence and prevalence of neuromyelitis optica: a systematic review. Int J MS Care. 2013; 15(3):113-118. [PubMed: 24453773]

20. Kira J. Multiple sclerosis in the Japanese population. Lancet Neurol. 2003; 2(2):117-127. [PubMed: 12849268]

21. Cabre P, Signate A, Olindo S, Merle H, Caparros-Lefebvre D, Bera O, et al. Role of return migration in the emergence of multiple sclerosis in the French West Indies. Brain. 2005; 128(Pt 12):2899-2910. [PubMed: 16183661]

22. Cabrera-Gomez JA, Kurtzke JF, Gonzalez-Quevedo A, Lara-Rodriguez R. An epidemiological study of neuromyelitis optica in Cuba. J Neurol. 2009; 256(1):35-44. [PubMed: 19224310]

23. Asgari N, Lillevang ST, Skejoe HP, Falah M, Stenager E, Kyvik KO. A population-based study of neuromyelitis optica in Caucasians. Neurology. 2011; 76(18):1589-1595. [PubMed: 21536639]

24. Cossburn M, Tackley G, Baker K, Ingram G, Burtonwood M, Malik G, et al. The prevalence of neuromyelitis optica in South East Wales. Eur J Neurol. 2012; 19(4):655-659. [PubMed: 21967235]

25. Mealy MA, Wingerchuk DM, Greenberg BM, Levy M. Epidemiology of neuromyelitis optica in the United States: a multicenter analysis. Arch Neurol. 2012; 69(9):1176-1180. [PubMed: 22733096]

26. Quek AM, McKeon A, Lennon VA, Mandrekar JN, Iorio R, Jiao Y, et al. Effects of age and sex on aquaporin-4 autoimmunity. Arch Neurol. 2012; 69(8):1039-1043. [PubMed: 22507888]

27. Pittock SJ. Neuromyelitis optica: a new perspective. Semin Neurol. 2008; 28(1):95-104. [PubMed: 18256990]

28. Wingerchuk DM, Weinshenker BG. Neuromyelitis optica: clinical predictors of a relapsing course and survival. Neurology. 2003; 60(5):848-853. [PubMed: 12629245]

29. Jiao Y, Fryer JP, Lennon VA, Jenkins SM, Quek AM, Smith CY, et al. Updated estimate of AQP4IgG serostatus and disability outcome in neuromyelitis optica. Neurology. 2013; 81(14):11971204. [PubMed: 23997151]

30. Jiao Y, Fryer JP, Lennon VA, McKeon A, Jenkins SM, Smith CY, et al. Aquaporin 4 IgG serostatus and outcome in recurrent longitudinally extensive transverse myelitis. JAMA Neurol. 2014; 71(1): 48-54. [PubMed: 24248262]

31. Collongues N, Cabre P, Marignier R, Zephir H, Papeix C, Audoin B, et al. A benign form of neuromyelitis optica: does it exist? Arch Neurol. 2011; 68(7):918-924. [PubMed: 21747032]

32. Visual function 15 years after optic neuritis: a final follow-up report from the Optic Neuritis Treatment Trial. Ophthalmology. 2008; 115(6):1079-1082. e5. [PubMed: 17976727]

33. Merle H, Olindo S, Bonnan M, Donnio A, Richer R, Smadja D, et al. Natural history of the visual impairment of relapsing neuromyelitis optica. Ophthalmology. 2007; 114(4):810-815. [PubMed: 17141316]

34. Ratchford JN, Quigg ME, Conger A, Frohman T, Frohman E, Balcer LJ, et al. Optical coherence tomography helps differentiate neuromyelitis optica and MS optic neuropathies. Neurology. 2009; 73(4):302-308. [PubMed: 19636050]

35. Naismith RT, Tutlam NT, Xu J, Klawiter EC, Shepherd J, Trinkaus K, et al. Optical coherence tomography differs in neuromyelitis optica compared with multiple sclerosis. Neurology. 2009; 72(12):1077-1082. [PubMed: 19307541]

36. Green AJ, Cree BA. Distinctive retinal nerve fibre layer and vascular changes in neuromyelitis optica following optic neuritis. J Neurol Neurosurg Psychiatry. 2009; 80(9):1002-1005. [PubMed: 19465415]

37. Nakamura M, Miyazawa I, Fujihara K, Nakashima I, Misu T, Watanabe S, et al. Preferential spinal central gray matter involvement in neuromyelitis optica. An MRI study. J Neurol. 2008; 255(2): 163-170. [PubMed: 18231705]

38. Flanagan EP, Weinshenker BG, Krecke KN, Lennon VA, Lucchinetti CF, McKeon A, et al. Short Myelitis Lesions in Aquaporin-4-IgG-Positive Neuromyelitis Optica Spectrum Disorders. JAMA Neurol. 2014 
39. Flanagan EP, Weinshenker B, Krecke K, Pittock SJ. Asymptomatic myelitis in neuromyelitis optica and autoimmune aquaporin-4 channelopathy. Neurol Clin Pract. 2014; 86:153-159.

40. Kim SM, Go MJ, Sung JJ, Park KS, Lee KW. Painful tonic spasm in neuromyelitis optica: incidence, diagnostic utility, and clinical characteristics. Arch Neurol. 2012; 69(8):1026-1031. [PubMed: 22473770]

41. Bradl M, Kanamori Y, Nakashima I, Misu T, Fujihara K, Lassmann H, et al. Pain in neuromyelitis optica--prevalence, pathogenesis and therapy. Nat Rev Neurol. 2014; 10(9):529-536. [PubMed: 25072195]

42. Kanamori Y, Nakashima I, Takai Y, Nishiyama S, Kuroda H, Takahashi T, et al. Pain in neuromyelitis optica and its effect on quality of life: a cross-sectional study. Neurology. 2011; 77(7):652-658. [PubMed: 21813781]

43. Zhao S, Mutch K, Elsone L, Nurmikko T, Jacob A. Neuropathic pain in neuromyelitis optica affects activities of daily living and quality of life. Mult Scler. 2014; 20(12):1658-1661. [PubMed: 24493470]

44. Pellkofer HL, Havla J, Hauer D, Schelling G, Azad SC, Kuempfel T, et al. The major brain endocannabinoid 2-AG controls neuropathic pain and mechanical hyperalgesia in patients with neuromyelitis optica. PLoS One. 2013; 8(8):e71500. [PubMed: 23951176]

45. Pittock SJ, Lennon VA, Krecke K, Wingerchuk DM, Lucchinetti CF, Weinshenker BG. Brain abnormalities in neuromyelitis optica. Arch Neurol. 2006; 63(3):390-396. [PubMed: 16533966]

46. Kiyat-Atamer A, Ekizoglu E, Tuzun E, Kurtuncu M, Shugaiv E, Akman-Demir G, et al. Long-term MRI findings in neuromyelitis optica: seropositive versus seronegative patients. Eur J Neurol. 2013; 20(5):781-787. [PubMed: 23279782]

47. Cabrera-Gomez JA, Kister I. Conventional brain MRI in neuromyelitis optica. Eur J Neurol. 2012; 19(6):812-819. [PubMed: 22040258]

48. Pittock SJ, Weinshenker BG, Lucchinetti CF, Wingerchuk DM, Corboy JR, Lennon VA. Neuromyelitis optica brain lesions localized at sites of high aquaporin 4 expression. Arch Neurol. 2006; 63(7):964-968. [PubMed: 16831965]

49. Ito S, Mori M, Makino T, Hayakawa S, Kuwabara S. "Cloud-like enhancement" is a magnetic resonance imaging abnormality specific to neuromyelitis optica. Ann Neurol. 2009; 66(3):425428. [PubMed: 19798642]

50. Matthews L, Marasco R, Jenkinson M, Kuker W, Luppe S, Leite MI, et al. Distinction of seropositive NMO spectrum disorder and MS brain lesion distribution. Neurology. 2013; 80(14): 1330-1337. [PubMed: 23486868]

51. Magana SM, Matiello M, Pittock SJ, McKeon A, Lennon VA, Rabinstein AA, et al. Posterior reversible encephalopathy syndrome in neuromyelitis optica spectrum disorders. Neurology. 2009; 72(8):712-717. [PubMed: 19237699]

52. Misu T, Fujihara K, Nakashima I, Sato S, Itoyama Y. Intractable hiccup and nausea with periaqueductal lesions in neuromyelitis optica. Neurology. 2005; 65(9):1479-1482. [PubMed: 16275842]

53. Apiwattanakul M, Popescu BF, Matiello M, Weinshenker BG, Lucchinetti CF, Lennon VA, et al. Intractable vomiting as the initial presentation of neuromyelitis optica. Ann Neurol. 2010; 68(5): 757-761. [PubMed: 21031587]

54. Iorio R, Lucchinetti CF, Lennon VA, Costanzi C, Hinson S, Weinshenker BG, et al. Syndrome of inappropriate antidiuresis may herald or accompany neuromyelitis optica. Neurology. 2011; 77(17):1644-1646. [PubMed: 21998320]

55. Guo Y, Lennon VA, Popescu BF, Grouse CK, Topel J, Milone M, et al. Autoimmune aquaporin-4 myopathy in neuromyelitis optica spectrum. JAMA Neurol. 2014; 71(8):1025-1029. [PubMed: 24911400]

56. Deguchi S, Deguchi K, Sato K, Yunoki T, Omote Y, Morimoto N, et al. HyperCKemia related to the initial and recurrent attacks of neuromyelitis optica. Intern Med. 2012; 51(18):2617-2620. [PubMed: 22989837]

57. Jeret JS, Suzuki N, Takahashi T, Fujihara K. Neuromyelitis optica preceded by hyperCKemia episode. Neurology. 2010; 75(24):2253. author reply-4. [PubMed: 21172851] 
58. Suzuki N, Takahashi T, Aoki M, Misu T, Konohana S, Okumura T, et al. Neuromyelitis optica preceded by hyperCKemia episode. Neurology. 2010; 74(19):1543-1545. [PubMed: 20458072]

59. Yokoyama N, Niino M, Takahashi T, Matsushima M, Maruo Y. Seroconversion of neuromyelitis optica spectrum disorder with hyperCKemia: a case report. Eur J Neurol. 2012; 19(12):e143. [PubMed: 23157245]

60. Di Filippo M, Franciotta D, Massa R, Di Gregorio M, Zardini E, Gastaldi M, et al. Recurrent hyperCKemia with normal muscle biopsy in a pediatric patient with neuromyelitis optica. Neurology. 2012; 79(11):1182-1184. [PubMed: 22933739]

61. Gelfand JM, Nolan R, Schwartz DM, Graves J, Green AJ. Microcystic macular oedema in multiple sclerosis is associated with disease severity. Brain. 2012; 135(Pt 6):1786-1793. [PubMed: 22539259]

62. Sotirchos ES, Saidha S, Byraiah G, Mealy MA, Ibrahim MA, Sepah YJ, et al. In-vivo identification of a novel retinal pathology in neuromyelitis optica. ECTRIMS Meeting Abstracts. 2012:657.

63. Banwell BL. Into the looking glass: predicting MS in children experiencing a first demyelinating event. Neurology. 2008; 71(13):962-963. [PubMed: 18809832]

64. McKeon A, Lennon VA, Lotze T, Tenenbaum S, Ness JM, Rensel M, et al. CNS aquaporin-4 autoimmunity in children. Neurology. 2008; 71(2):93-100. [PubMed: 18509092]

65. Saadoun S, Waters P, Leite MI, Bennett JL, Vincent A, Papadopoulos MC. Neuromyelitis optica IgG causes placental inflammation and fetal death. J Immunol. 2013; 191(6):2999-3005. [PubMed: 23935196]

66. Kim W, Kim SH, Nakashima I, Takai Y, Fujihara K, Leite MI, et al. Influence of pregnancy on neuromyelitis optica spectrum disorder. Neurology. 2012; 78(16):1264-1267. [PubMed: 22491862]

67. Bourre B, Marignier R, Zephir H, Papeix C, Brassat D, Castelnovo G, et al. Neuromyelitis optica and pregnancy. Neurology. 2012; 78(12):875-879. [PubMed: 22402855]

68. Waters PJ, McKeon A, Leite MI, Rajasekharan S, Lennon VA, Villalobos A, et al. Serologic diagnosis of NMO: a multicenter comparison of aquaporin-4-IgG assays. Neurology. 2012; 78(9): 665-671. discussion 9. [PubMed: 22302543]

69. Fryer JP, Lennon VA, Pittock SJ, Jenkins SM, Fallier-Becker P, Clardy SL, et al. AQP4 autoantibody assay performance in clinical laboratory service. Neurol Neuroimmunol Neuroinflamm. 2014; 1(1):e11. [PubMed: 25340055]

70. Kitley J, Leite MI, Kuker W, Quaghebeur G, George J, Waters P, et al. Longitudinally extensive transverse myelitis with and without aquaporin 4 antibodies. JAMA Neurol. 2013; 70(11):13751381. [PubMed: 23999580]

71. Iyer A, Elsone L, Appleton R, Jacob A. A review of the current literature and a guide to the early diagnosis of autoimmune disorders associated with neuromyelitis optica. Autoimmunity. 2014; 47(3):154-161. [PubMed: 24512514]

72. Zhang B, Zhong Y, Wang Y, Dai Y, Qiu W, Zhang L, et al. Neuromyelitis optica spectrum disorders without and with autoimmune diseases. BMC Neurol. 2014; 14:162. [PubMed: 25135481]

73. Pittock SJ, Lennon VA, de Seze J, Vermersch P, Homburger HA, Wingerchuk DM, et al. Neuromyelitis optica and non organ-specific autoimmunity. Arch Neurol. 2008; 65(1):78-83. [PubMed: 18195142]

74. McKeon A, Lennon VA, Jacob A, Matiello M, Lucchinetti CF, Kale N, et al. Coexistence of myasthenia gravis and serological markers of neurological autoimmunity in neuromyelitis optica. Muscle Nerve. 2009; 39(1):87-90. [PubMed: 19086079]

75. Armagan H, Tuzun E, Icoz S, Birisik O, Ulusoy C, Demir G, et al. Long extensive transverse myelitis associated with aquaporin- 4 antibody and breast cancer: favorable response to cancer treatment. J Spinal Cord Med. 2012; 35(4):267-269. [PubMed: 22925754]

76. De Santis G, Caniatti L, De Vito A, De Gennaro R, Granieri E, Tola MR. A possible paraneoplastic neuromyelitis optica associated with lung cancer. Neurol Sci. 2009; 30(5):397-400. [PubMed: 19565183]

77. Frasquet M, Bataller L, Torres-Vega E, Duran-Moreno M, Garcia-Verdugo JM, Sevilla T, et al. Longitudinally extensive transverse myelitis with AQP4 antibodies revealing ovarian teratoma. J Neuroimmunol. 2013; 263(1-2):145-147. [PubMed: 23899665] 
78. Pittock SJ, Lennon VA. Aquaporin-4 autoantibodies in a paraneoplastic context. Arch Neurol. 2008; 65(5):629-632. [PubMed: 18474738]

79. Al-Harbi T, Al-Sarawi A, Binfalah M, Dermime S. Paraneoplastic neuromyelitis optica spectrum disorder associated with stomach carcinoid tumor. Hematol Oncol Stem Cell Ther. 2014; 7(3): 116-119. [PubMed: 24954081]

80. Ontaneda D, Fox RJ. Is neuromyelitis optica with advanced age of onset a paraneoplastic disorder? Int J Neurosci. 2014; 124(7):509-511. [PubMed: 24111490]

81. Uzawa A, Mori M, Ito M, Uchida T, Hayakawa S, Masuda S, et al. Markedly increased CSF interleukin-6 levels in neuromyelitis optica, but not in multiple sclerosis. J Neurol. 2009; 256(12): 2082-2084. [PubMed: 19655191]

82. Icoz S, Tuzun E, Kurtuncu M, Durmus H, Mutlu M, Eraksoy M, et al. Enhanced IL-6 production in aquaporin-4 antibody positive neuromyelitis optica patients. Int J Neurosci. 2010; 120(1):71-75. [PubMed: 20128675]

83. Ayzenberg I, Kleiter I, Schroder A, Hellwig K, Chan A, Yamamura T, et al. Interleukin 6 receptor blockade in patients with neuromyelitis optica nonresponsive to anti-CD20 therapy. JAMA Neurol. 2013; 70(3):394-397. [PubMed: 23358868]

84. Kieseier BC, Stuve O, Dehmel T, Goebels N, Leussink VI, Mausberg AK, et al. Disease amelioration with tocilizumab in a treatment-resistant patient with neuromyelitis optica: implication for cellular immune responses. JAMA Neurol. 2013; 70(3):390-393. [PubMed: 23599943]

85. Misu T, Takano R, Fujihara K, Takahashi T, Sato S, Itoyama Y. Marked increase in cerebrospinal fluid glial fibrillar acidic protein in neuromyelitis optica: an astrocytic damage marker. J Neurol Neurosurg Psychiatry. 2009; 80(5):575-577. [PubMed: 19372295]

86. Storoni M, Petzold A, Plant GT. The use of serum glial fibrillary acidic protein measurements in the diagnosis of neuromyelitis optica spectrum optic neuritis. PLoS One. 2011; 6(8):e23489. [PubMed: 21876753]

87. Takano R, Misu T, Takahashi T, Sato S, Fujihara K, Itoyama Y. Astrocytic damage is far more severe than demyelination in NMO: a clinical CSF biomarker study. Neurology. 2010; 75(3):208216. [PubMed: 20644148]

88. Saadoun S, Papadopoulos MC, Watanabe H, Yan D, Manley GT, Verkman AS. Involvement of aquaporin-4 in astroglial cell migration and glial scar formation. J Cell Sci. 2005; 118(Pt 24): 5691-5698. [PubMed: 16303850]

89. Manley GT, Fujimura M, Ma T, Noshita N, Filiz F, Bollen AW, et al. Aquaporin-4 deletion in mice reduces brain edema after acute water intoxication and ischemic stroke. Nat Med. 2000; 6(2):159163. [PubMed: 10655103]

90. Papadopoulos MC, Manley GT, Krishna S, Verkman AS. Aquaporin-4 facilitates reabsorption of excess fluid in vasogenic brain edema. Faseb J. 2004; 18(11):1291-1293. [PubMed: 15208268]

91. Verkman AS, Anderson MO, Papadopoulos MC. Aquaporins: important but elusive drug targets. Nat Rev Drug Discov. 2014; 13(4):259-277. [PubMed: 24625825]

92. Saadoun S, Papadopoulos MC. Role of membrane complement regulators in neuromyelitis optica. Mult Scler. 2015 Feb 19. (Epub ahead of print).

93. Neely JD, Christensen BM, Nielsen S, Agre P. Heterotetrameric composition of aquaporin-4 water channels. Biochemistry. 1999; 38(34):11156-11163. [PubMed: 10460172]

94. Jung JS, Bhat RV, Preston GM, Guggino WB, Baraban JM, Agre P. Molecular characterization of an aquaporin cDNA from brain: candidate osmoreceptor and regulator of water balance. Proc Natl Acad Sci U S A. 1994; 91(26):13052-13056. [PubMed: 7528931]

95. Yang B, Ma T, Verkman AS. cDNA cloning, gene organization, and chromosomal localization of a human mercurial insensitive water channel. Evidence for distinct transcriptional units. J Biol Chem. 1995; 270(39):22907-22913. [PubMed: 7559426]

96. Lu M, Lee MD, Smith BL, Jung JS, Agre P, Verdijk MA, et al. The human AQP4 gene: definition of the locus encoding two water channel polypeptides in brain. Proc Natl Acad Sci U S A. 1996; 93(20):10908-10912. [PubMed: 8855281]

97. Wolburg H. Orthogonal arrays of intramembranous particles: a review with special reference to astrocytes. J Hirnforsch. 1995; 36(2):239-258. [PubMed: 7615928] 
98. Wolburg H, Wolburg-Buchholz K, Fallier-Becker P, Noell S, Mack AF. Structure and functions of aquaporin-4-based orthogonal arrays of particles. Int Rev Cell Mol Biol. 2011; 287:1-41. [PubMed: 21414585]

99. Furman CS, Gorelick-Feldman DA, Davidson KG, Yasumura T, Neely JD, Agre P, et al. Aquaporin-4 square array assembly: opposing actions of M1 and M23 isoforms. Proc Natl Acad Sci U S A. 2003; 100(23):13609-13614. [PubMed: 14597700]

100. Nicchia GP, Mastrototaro M, Rossi A, Pisani F, Tortorella C, Ruggieri M, et al. Aquaporin-4 orthogonal arrays of particles are the target for neuromyelitis optica autoantibodies. Glia. 2009; 57(13):1363-1373. [PubMed: 19229993]

101. Iorio R, Fryer JP, Hinson SR, Fallier-Becker P, Wolburg H, Pittock SJ, et al. Astrocytic autoantibody of neuromyelitis optica (NMO-IgG) binds to aquaporin-4 extracellular loops, monomers, tetramers and high order arrays. J Autoimmun. 2013; 40:21-27. [PubMed: 22906356]

102. Hinson SR, Pittock SJ, Lucchinetti CF, Roemer SF, Fryer JP, Kryzer TJ, et al. Pathogenic potential of IgG binding to water channel extracellular domain in neuromyelitis optica. Neurology. 2007; 69(24):2221-2231. [PubMed: 17928579]

103. Hinson SR, Romero MF, Popescu BF, Lucchinetti CF, Fryer JP, Wolburg H, et al. Molecular outcomes of neuromyelitis optica (NMO)-IgG binding to aquaporin-4 in astrocytes. Proc Natl Acad Sci U S A. 2012; 109(4):1245-1250. [PubMed: 22128336]

104. Hinson SR, Roemer SF, Lucchinetti CF, Fryer JP, Kryzer TJ, Chamberlain JL, et al. Aquaporin-4binding autoantibodies in patients with neuromyelitis optica impair glutamate transport by downregulating EAAT2. J Exp Med. 2008; 205(11):2473-2481. [PubMed: 18838545]

105. Marignier R, Nicolle A, Watrin C, Touret M, Cavagna S, Varrin-Doyer M, et al. Oligodendrocytes are damaged by neuromyelitis optica immunoglobulin G via astrocyte injury. Brain. 2010; 133(9):2578-2591. [PubMed: 20688809]

106. Zeng XN, Sun XL, Gao L, Fan Y, Ding JH, Hu G. Aquaporin-4 deficiency down-regulates glutamate uptake and GLT-1 expression in astrocytes. Mol Cell Neurosci. 2007; 34(1):34-39. [PubMed: 17074507]

107. Coulter DA, Eid T. Astrocytic regulation of glutamate homeostasis in epilepsy. Glia. 2012; 60(8): 1215-1226. [PubMed: 22592998]

108. Danbolt NC. Glutamate uptake. Prog Neurobiol. 2001; 65(1):1-105. [PubMed: 11369436]

109. Howe CL, Kaptzan T, Magana SM, Ayers-Ringler JR, LaFrance-Corey RG, Lucchinetti CF. Neuromyelitis optica IgG stimulates an immunological response in rat astrocyte cultures. Glia. 2014; 62(5):692-708. [PubMed: 24492996]

110. Lucchinetti CF, Mandler RN, McGavern D, Bruck W, Gleich G, Ransohoff RM, et al. A role for humoral mechanisms in the pathogenesis of Devic's neuromyelitis optica. Brain. 2002; 125(Pt 7): 1450-1461. [PubMed: 12076996]

111. Matsushita T, Tateishi T, Isobe N, Yonekawa T, Yamasaki R, Matsuse D, et al. Characteristic cerebrospinal fluid cytokine/chemokine profiles in neuromyelitis optica, relapsing remitting or primary progressive multiple sclerosis. PLoS One. 2013; 8(4):e61835. [PubMed: 23637915]

112. Saadoun S, Waters P, MacDonald C, Bell BA, Vincent A, Verkman AS, et al. Neutrophil protease inhibition reduces neuromyelitis optica-immunoglobulin G-induced damage in mouse brain. Ann Neurol. 2012; 71(3):323-333. [PubMed: 22374891]

113. Barnum SR. Complement biosynthesis in the central nervous system. Crit Rev Oral Biol Med. 1995; 6(2):132-146. [PubMed: 7548620]

114. Misu T, Fujihara K, Kakita A, Konno H, Nakamura M, Watanabe S, et al. Loss of aquaporin 4 in lesions of neuromyelitis optica: distinction from multiple sclerosis. Brain. 2007; 130(Pt 5):12241234. [PubMed: 17405762]

115. Lucchinetti CF, Guo Y, Popescu BF, Fujihara K, Itoyama Y, Misu T. The pathology of an autoimmune astrocytopathy: lessons learned from neuromyelitis optica. Brain Pathol. 2014; 24(1):83-97. [PubMed: 24345222]

116. Saadoun S, Waters P, Bell BA, Vincent A, Verkman AS, Papadopoulos MC. Intra-cerebral injection of neuromyelitis optica immunoglobulin $\mathrm{G}$ and human complement produces neuromyelitis optica lesions in mice. Brain. 2010; 133(Pt 2):349-361. [PubMed: 20047900] 
117. Saadoun S, Waters P, Macdonald C, Bridges LR, Bell BA, Vincent A, et al. T cell deficiency does not reduce lesions in mice produced by intracerebral injection of NMO-IgG and complement. $\mathrm{J}$ Neuroimmunol. 2011; 235(1-2):27-32. [PubMed: 21492943]

118. Bennett JL, Lam C, Kalluri SR, Saikali P, Bautista K, Dupree C, et al. Intrathecal pathogenic antiaquaporin-4 antibodies in early neuromyelitis optica. Ann Neurol. 2009; 66(5):617-629. [PubMed: 19938104]

119. Bradl M, Misu T, Takahashi T, Watanabe M, Mader S, Reindl M, et al. Neuromyelitis optica: pathogenicity of patient immunoglobulin in vivo. Ann Neurol. 2009; 66(5):630-643. [PubMed: 19937948]

120. Kinoshita M, Nakatsuji Y, Kimura T, Moriya M, Takata K, Okuno T, et al. Neuromyelitis optica: Passive transfer to rats by human immunoglobulin. Biochem Biophys Res Commun. 2009; 386(4):623-627. [PubMed: 19545538]

121. Kinoshita M, Nakatsuji Y, Kimura T, Moriya M, Takata K, Okuno T, et al. Anti-aquaporin-4 antibody induces astrocytic cytotoxicity in the absence of CNS antigen-specific T cells. Biochem Biophys Res Commun. 2010; 394(1):205-210. [PubMed: 20188706]

122. Roemer SF, Parisi JE, Lennon VA, Benarroch EE, Lassmann H, Bruck W, et al. Pattern-specific loss of aquaporin-4 immunoreactivity distinguishes neuromyelitis optica from multiple sclerosis. Brain. 2007; 130(Pt 5):1194-1205. [PubMed: 17282996]

123. Popescu BF, Lennon VA, Parisi JE, Howe CL, Weigand SD, Cabrera-Gomez JA, et al. Neuromyelitis optica unique area postrema lesions: nausea, vomiting, and pathogenic implications. Neurology. 2011; 76(14):1229-1237. [PubMed: 21368286]

124. Popescu BF, Guo Y, Jentoft ME, Parisi JE, Lennon VA, Pittock SJ, et al. Diagnostic utility of aquaporin-4 in the analysis of active demyelinating lesions. Neurology. 2015; 84(2):148-158. [PubMed: 25503621]

125. Filippi M, Rocca MA, Moiola L, Martinelli V, Ghezzi A, Capra R, et al. MRI and magnetization transfer imaging changes in the brain and cervical cord of patients with Devic's neuromyelitis optica. Neurology. 1999; 53(8):1705-1710. [PubMed: 10563616]

126. Rocca MA, Agosta F, Mezzapesa DM, Martinelli V, Salvi F, Ghezzi A, et al. Magnetization transfer and diffusion tensor MRI show gray matter damage in neuromyelitis optica. Neurology. 2004; 62(3):476-478. [PubMed: 14872036]

127. Popescu BF, Parisi JE, Cabrera-Gomez JA, Newell K, Mandler RN, Pittock SJ, et al. Absence of cortical demyelination in neuromyelitis optica. Neurology. 2010; 75(23):2103-2109. [PubMed: 21135384]

128. Papadopoulos MC, Bennett JL, Verkman AS. Treatment of neuromyelitis optica: state-of-the-art and emerging therapies. Nat Rev Neurol. 2014; 10(9):493-506. [PubMed: 25112508]

129. Pittock SJ, Lennon VA, McKeon A, Mandrekar J, Weinshenker BG, Lucchinetti CF, et al. Eculizumab in AQP4-IgG-positive relapsing neuromyelitis optica spectrum disorders: an openlabel pilot study. Lancet Neurol. 2013; 12(6):554-602. [PubMed: 23623397]

130. Chihara N, Aranami T, Sato W, Miyazaki Y, Miyake S, Okamoto T, et al. Interleukin 6 signaling promotes anti-aquaporin 4 autoantibody production from plasmablasts in neuromyelitis optica. Proc Natl Acad Sci U S A. 2011; 108(9):3701-3706. [PubMed: 21321193]

131. Araki M, Matsuoka T, Miyamoto K, Kusunoki S, Okamoto T, Murata M, et al. Efficacy of the anti-IL-6 receptor antibody tocilizumab in neuromyelitis optica: a pilot study. Neurology. 2014; 82(15):1302-1306. [PubMed: 24634453]

132. Tedder TF. CD19: a promising B cell target for rheumatoid arthritis. Nat Rev Rheumatol. 2009; 5(10):572-577. [PubMed: 19798033]

133. Hammer O. CD19 as an attractive target for antibody-based therapy. MAbs. 2012; 4(5):571-577. [PubMed: 22820352]

134. Tradtrantip L, Zhang H, Saadoun S, Phuan PW, Lam C, Papadopoulos MC, et al. Antiaquaporin-4 monoclonal antibody blocker therapy for neuromyelitis optica. Ann Neurol. 2012; 71(3):314-322. [PubMed: 22271321]

135. Dalmau J, Lancaster E, Martinez-Hernandez E, Rosenfeld MR, Balice-Gordon R. Clinical experience and laboratory investigations in patients with anti-NMDAR encephalitis. Lancet Neurol. 2011; 10(1):63-74. [PubMed: 21163445] 
136. Titulaer MJ, McCracken L, Gabilondo I, Armangue T, Glaser C, Iizuka T, et al. Treatment and prognostic factors for long-term outcome in patients with anti-NMDA receptor encephalitis: an observational cohort study. Lancet Neurol. 2013; 12(2):157-165. [PubMed: 23290630]

137. Mader S, Gredler V, Schanda K, Rostasy K, Dujmovic I, Pfaller K, et al. Complement activating antibodies to myelin oligodendrocyte glycoprotein in neuromyelitis optica and related disorders. J Neuroinflammation. 2011; 8:184. [PubMed: 22204662]

138. Kitley J, Woodhall M, Waters P, Leite MI, Devenney E, Craig J, et al. Myelin-oligodendrocyte glycoprotein antibodies in adults with a neuromyelitis optica phenotype. Neurology. 2012; 79(12):1273-1277. [PubMed: 22914827]

139. Sato DK, Callegaro D, Lana-Peixoto MA, Waters PJ, de Haidar Jorge FM, Takahashi T, et al. Distinction between MOG antibody-positive and AQP4 antibody-positive NMO spectrum disorders. Neurology. 2014; 82(6):474-481. [PubMed: 24415568]

140. Kitley J, Waters P, Woodhall M, Leite MI, Murchison A, George J, et al. Neuromyelitis optica spectrum disorders with aquaporin-4 and myelin-oligodendrocyte glycoprotein antibodies: a comparative study. JAMA Neurol. 2014; 71(3):276-283. [PubMed: 24425068]

141. Zamvil SS, Slavin AJ. Does MOG Ig-positive AQP4-seronegative opticospinal inflammatory disease justify a diagnosis of NMO spectrum disorder? Neurol Neuroimmunol Neuroinflamm. 2015; 2(1):e62. [PubMed: 25635259]

142. Kimbrough DJ, Fujihara K, Jacob A, Lana-Peixoto MA, Leite MI, Levy M, Marignier R, et al. Treatment of neuromyelitis optica: Review and recommendations. Multiple Sclerosis and Related Disorders. 2012; 1:180-187. [PubMed: 24555176] 


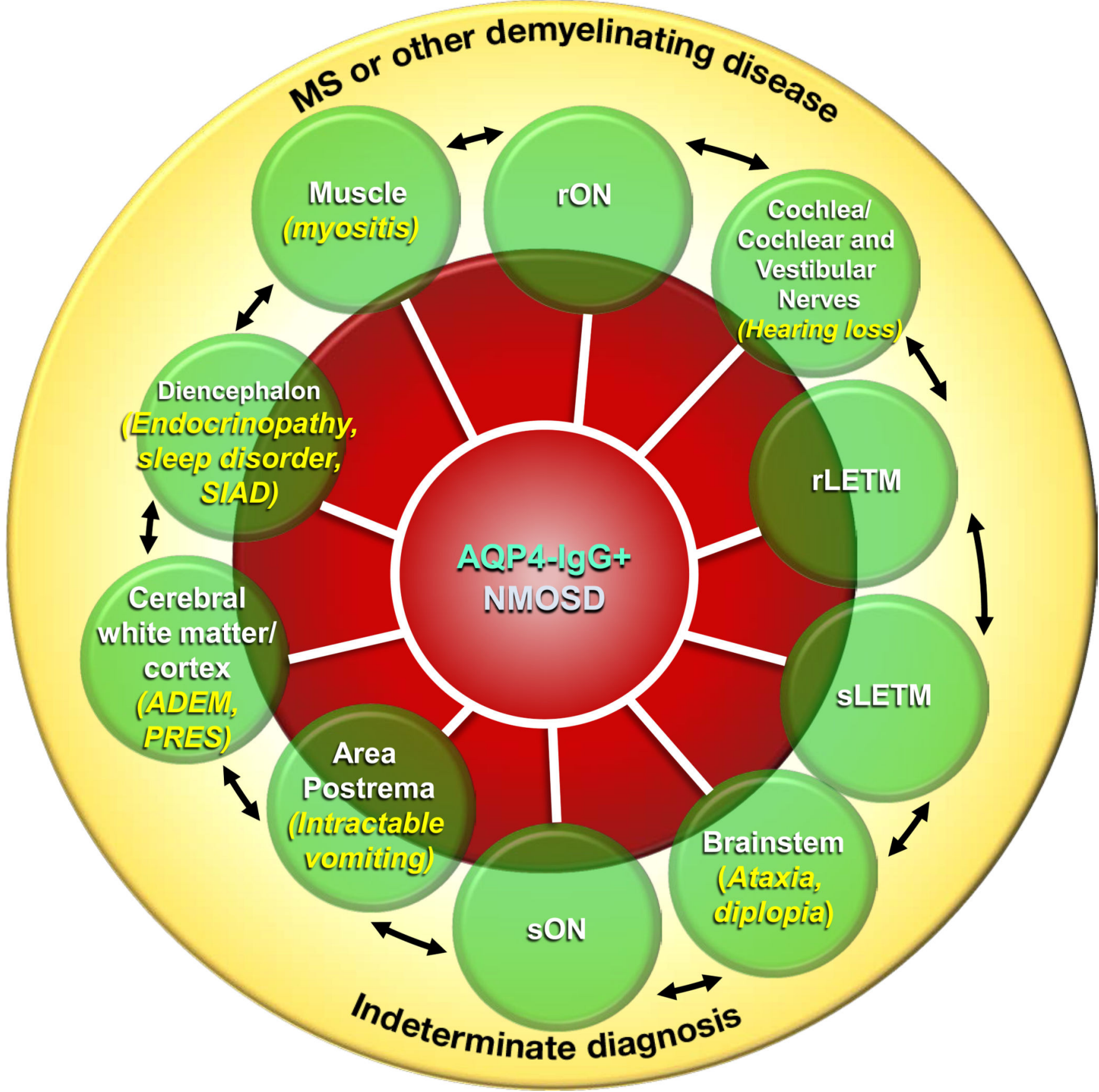

Figure 1.

Autoimmune aquaporin-4 (AQP4) channelopathy. Schematic for proposed diagnostic criteria incorporating the expanding clinical phenotypes of neuromyelitis optica spectrum disorders (NMOSD). This schema is based on the proposal that the core diagnostic criteria for any NMOSD requires the presence of the AQP4-immunoglobulin (IgG; red) and assumes no false positivity. Seropositivity for AQP4-IgG must be interpreted within the clinical context. The absence of the biomarker (yellow outer circle) could indicate an alternative diagnosis, such as multiple sclerosis, another demyelinating disease, or an indeterminate disorder. 
Some patients may have autoimmune MOG oligodendrogliopathy. Each neurological manifestation is represented by a circle. The area of the circle overlapping with the red AQP4-IgG ${ }^{+}$circle represents an approximation of the proportion of patients with that neurological manifestation considered NMOSD (e.g., $<5 \%$ of patients with single-episode optic neuritis; $5-25 \%$ of patients with recurrent optic neuritis; $40 \%$ of patients with singleepisode longitudinally extensive transverse myelitis (LETM); 70-90\% of patients with recurrent LETM). The area of the circle outside (yellow) the red AQP4-IgG ${ }^{+}$circle does not fulfill criteria for NMOSD. The arrows signify that neurological manifestations commonly coexist; for example, patients might present with or have a history of more than one neurological manifestation, such as optic neuritis and intractable vomiting, syndrome of inappropriate antidiuresis and LETM, LETM and brain stem disorder, and LETM and posterior reversible encephalopathy syndrome. Only rarely is myositis encountered. Adapted from Ref. 11 with permission from Wiley. 


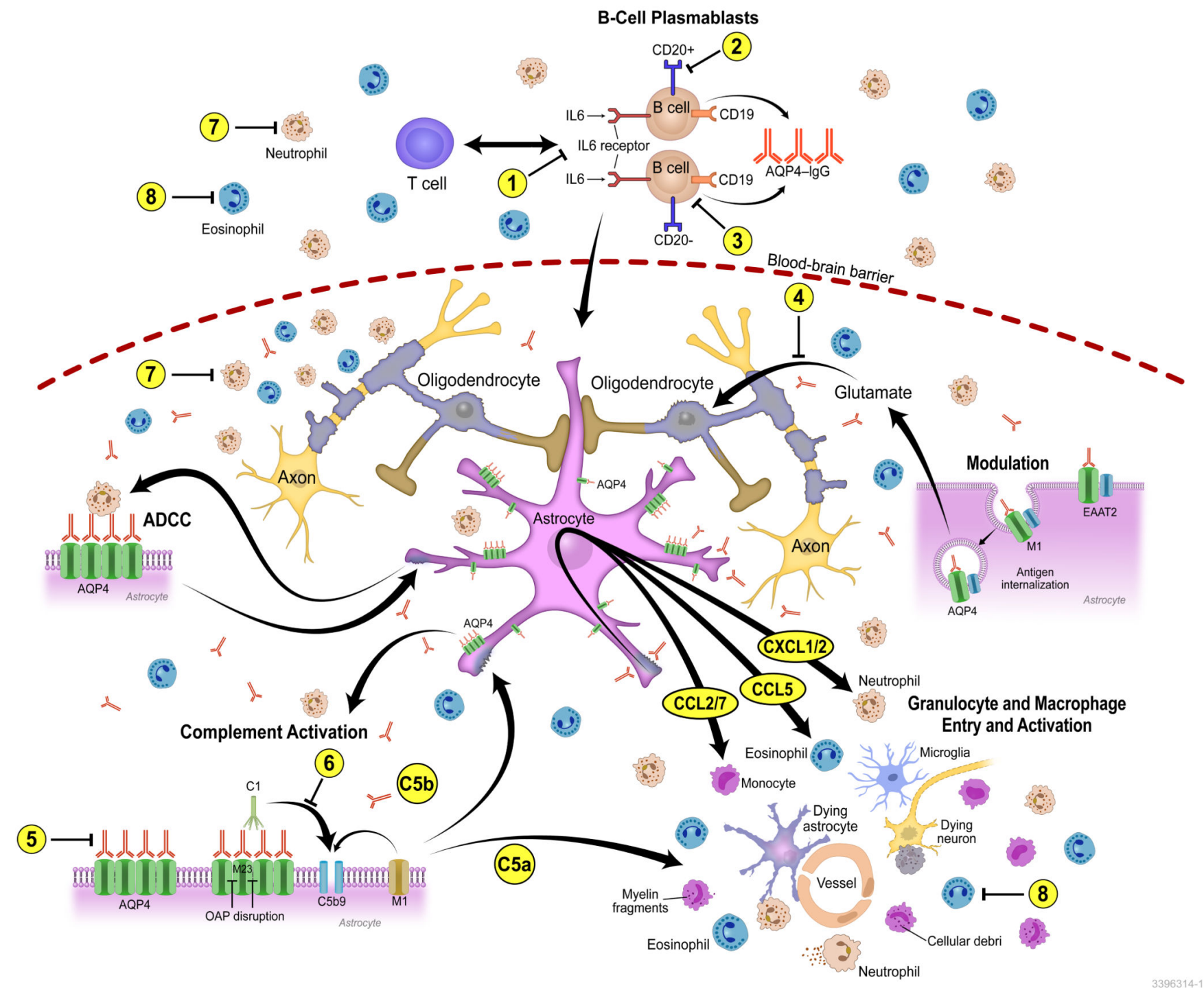

Figure 2.

Mechanisms of NMO pathogenesis and pharmacologic targets. NMO lesions have a complex spectrum of characteristics indicating multiple pathogenic mechanisms. In NMOSD, the immunizing event is not known. AQP4-IgG produced by plasma cells and plasmablasts penetrates the CNS through endothelial transcytosis or at areas of relative blood-brain barrier permeability or injury (some may be produced within the CNS). Binding of NMO IgG to AQP4 on the surface of astrocytes induces an inflammatory reactive stress response that results in transcriptional and translational events within the astrocyte that promote the primary recruitment of granulocytes to the CNS. In vitro studies have demonstrated upregulation of adhesion factors such as ICAM-1 and VCAM-1, the initiation of oxidative stress response pathways involving SOD2 and ceruloplasmin, and the upregulation of inflammasome components such as caspase- 1 and various proteasome subunits, inducing a massive cytokine and chemokine response (e.g., CXCL1/2 targeting neutrophils; CCL2 and CCL7 targeting monocytes, and CCL5 targeting eosinophils). Antibody-dependent astrocyte damage involving complement-dependent cytotoxicity and 
antibody-dependent cellular cytotoxicity (ADCC) mechanisms amplify inflammation and contribute to additional oligodendrocyte injury, demyelination, and neuronal loss. The numbers (1-8) indicate some pharmacological targets in NMO including approved drugs under evaluation for repurposing, drugs in preclinical development, and drugs at early, proof-of-concept stage: (1) IL-6 inhibitors: tocilizumab (Actemra, Toactemra; Genentech); SA237 (Chugai): phase III strial due to start enrolling patients soon; (2) CD20: rituximab; (3) CD19: MEDI-551 (Medimmune LLC), phase III trial enrolling patients; (4) glutamate antagonists; (5) AQP4-IgG blocking and inactivation strategies: high-affinity, nonpathogenic anti-AQP4 antibody (aquaporumab) competes with pathogenic AQP4-IgG for AQP4 binding; (6) complement activation pathways and complement drug targets: eculizumab (Soliris) inhibits C5 and is now in phase III trial; C1inh (Cinryse) inhibits C1, phase I completed; (7) anti-neutrophil: sivelestat (Elaspol), phase I and II recruiting patients; and (8) anti-eosinophil: antihistamines, cetirizine, and ketotifen reduce cytotoxicity mediated by AQP4-IgG and eosinophils in in vitro models. Eosinophil-stabilizing agents are currently being studied in small numbers of patients with NMO. 


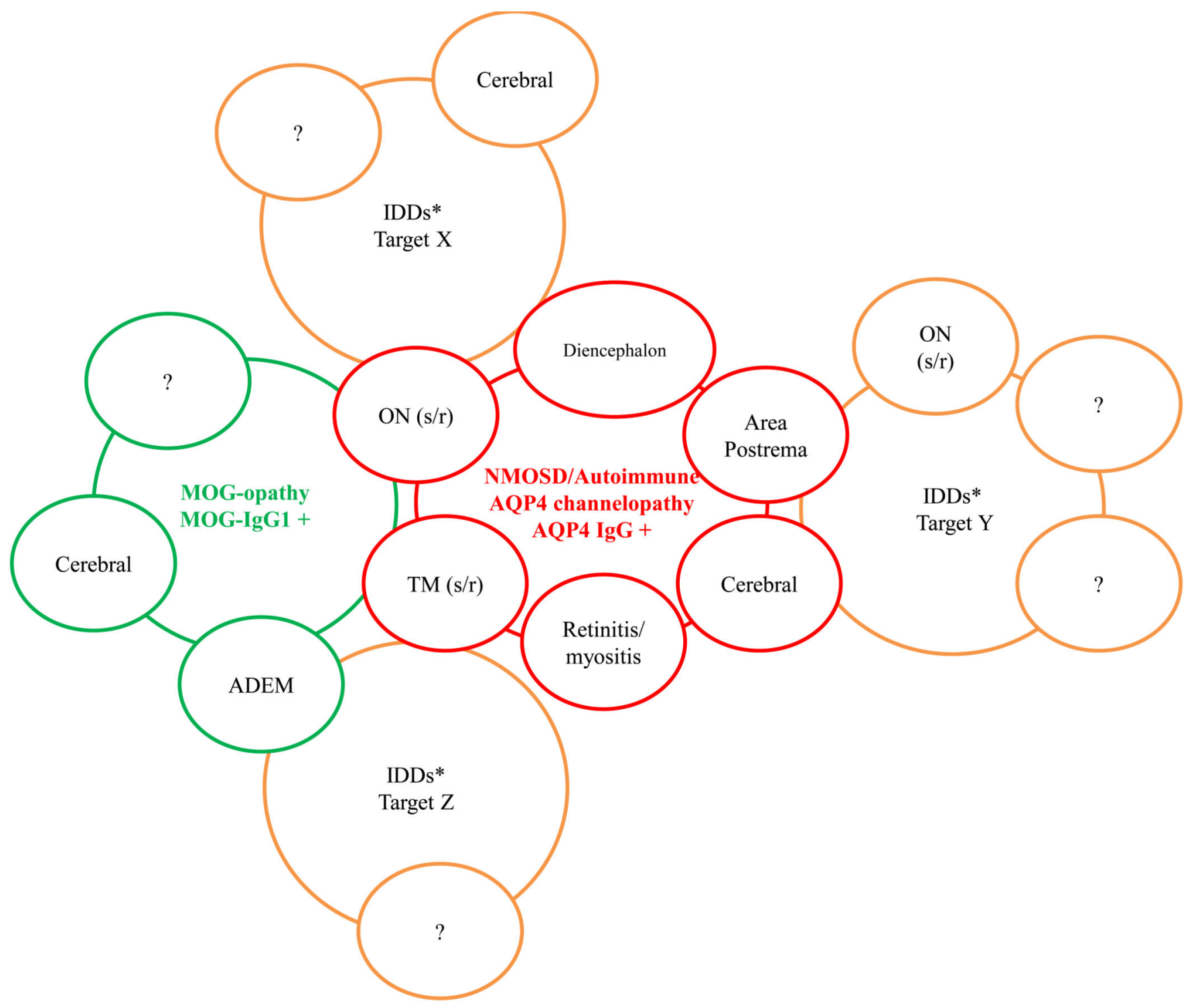

Figure 3.

Molecular-based approach to classification of inflammatory demyelinating diseases (IDDs). Schematic for proposed classification of CNS IDDs according to the molecular target. The circles illustrate the clinical phenotypic overlap for IDDs where the molecular target is known (AQP4 in red and MOG in green) or yet to be discovered (orange circles indicate hypothetical clinical phenotypic overlap and question marks indicate clinical symptoms or signs to be determined). This schema recognizes that clinical phenotype may be shared (for example optic neuritis or transverse myelitis) though the immunopathogenic mechanisms may differ (astrocytopathy in AQP4 autoimmunity and oligodendrogliopathy in MOG autoimmunity). Recognition of such immunopathogenic differences will likely be important as more individualized and mechanistically targeted therapies become available. 
Table 1

Comparison of clinical, radiological and laboratory clinical characteristics of neuromyelitis optica spectrum disorders (NMOSD) and multiple sclerosis

\begin{tabular}{|c|c|c|}
\hline & Multiple sclerosis & NMOSD \\
\hline Definition & $\begin{array}{l}\text { Central nervous system symptoms and signs } \\
\text { indicating involvement of the white-matter } \\
\text { tracts. } \\
\text { Evidence of dissemination in space and time on } \\
\text { the basis of clinical or MRI findings. No better } \\
\text { explanation }\end{array}$ & $\begin{array}{l}\text { NMO: Transverse myelitis and optic neuritis } \\
\text { At least two of the following: brain MRI, non- } \\
\text { diagnostic for multiple sclerosis; spinal cord lesion } \\
\text { extending over three or more vertebral segments; } \\
\text { or seropositive for AQP4-IgG } \\
\text { NMOSD ( see Fig. } 1 \text { for definition) }\end{array}$ \\
\hline AQP4-IgG positivity & $0 \%$ & $\begin{array}{l}\text { NMO: } 80-90 \% \\
\text { NMOSD: must be positive as per diagnostic } \\
\text { criteria (Fig.1) }\end{array}$ \\
\hline Clinical onset and course & $\begin{array}{l}85 \% \text { Relapsing/remitting, } 15 \% \text { Primary/ } \\
\text { progressive. Not monophasic }\end{array}$ & $\begin{array}{l}\text { Onset always with relapse } \\
\text { Greater than } 90 \% \text { relapsing course }\end{array}$ \\
\hline Median age of onset (years) & 29 & 39 \\
\hline Sex (female:male) & $2: 1$ & $9: 1$ \\
\hline Secondary progressive course & Common & Rare \\
\hline MRI: brain & Periventricular white-matter ovoid lesions & $\begin{array}{l}\text { Usually non-specific white-matter lesions; } 10 \% \\
\text { unique hypothalamic, corpus callosal/splenial, } \\
\text { periventricular, periaqueductal, medullary, brain } \\
\text { stem lesions } \\
\text { Note cloud like enhancement } \\
\text { Occasional extensive and symmetric lesions }\end{array}$ \\
\hline MRI: spinal cord & Short-segment peripheral lesions & $\begin{array}{l}\text { Longitudinally extensive ( } \geq 3 \text { vertebral segments) } \\
\text { central lesions }\end{array}$ \\
\hline $\begin{array}{l}\text { CSF white-blood-cell number and } \\
\text { differential count }\end{array}$ & Mild pleocytosis; Mononuclear & $\begin{array}{l}\text { Occasional prominent pleocytosis; } \\
\text { Polymorphonuclear cells and mononuclear cells; } \\
\text { IL-6 high; GFAP high }\end{array}$ \\
\hline CSF oligoclonal bands & $85 \%$ & $15-30 \%$ \\
\hline Coexisting autoimmune disease & Rare & Common: SLE, SS, MG, Thyroid, APL \\
\hline Attack prevention therapies & $\begin{array}{l}\text { Interferon-beta, fingolimod, rituximab, } \\
\text { natalizumab, glatiramer acetate }\end{array}$ & $\begin{array}{l}\text { Prednisone, azathioprine, mycophenolate mofetil, } \\
\text { rituximab, mitoxantrone }\end{array}$ \\
\hline
\end{tabular}

APL, antiphospholipid syndrome; AQP4, aquaporin-4; CSF, cerebrospinal fluid; GFAP, global fibrillary astrocy interleukin-6; MG, myasthenia gravis; MRI, magnetic resonance imaging; NMO, neuromyelitis optica; NMOSD, SLE, systemic lupus erythematosus; SS, Sjogren's syndrome

Reused with permission from Wiley. Originally from Iorio R and Pittock SJ. (2014). Neuromyelitis optica and the evolving spectrum of autoimmune aquaporin-4 channelopathies. Clinical \& Experimental Neuroimmunology. 5:175-187. 
Table 2

Current attack-prevention therapies in NMO. Modified from Ref. 142.

\begin{tabular}{|c|c|c|c|c|}
\hline Medication & Dose and schedule & Monitoring & $\begin{array}{l}\text { Treatment change } \\
\text { consideration }\end{array}$ & $\begin{array}{l}\text { Mode of action and } \\
\text { ARR reduction }\end{array}$ \\
\hline $\begin{array}{l}\text { Azathioprine (+ } \\
\text { prednisone) (PO) }\end{array}$ & $\begin{array}{l}2-3 \mathrm{mg} / \mathrm{kg} / \text { day }(+30 \mathrm{mg} / \\
\text { day): } 1-2 \text { daily doses } \\
\text { (prednisone taper after 6- } \\
9 \text { months) }\end{array}$ & $\begin{array}{l}\text { Initial: TPMT activity } \\
\text { assay. Periodic: MCV } \\
\text { increase } \geq 5 \text { points from } \\
\text { baseline; monthly liver } \\
\text { function tests for first } 6 \\
\text { months, then quarterly; } \\
\text { maintain absolute } \\
\text { neutrophil counts }>1000 \\
\text { cells } / \mu \mathrm{L} \text {. }\end{array}$ & $\begin{array}{l}\text { If MCV did not rise on } \\
\text { initial dose, consider } \\
\text { increase by } 0.5-1 \mathrm{mg} / \mathrm{kg} / \\
\text { day. Or consider increasing } \\
\text { dose or duration of } \\
\text { prednisone. Switch to } \\
\text { rituximab or mycophenolate } \\
\text { mofetil. }\end{array}$ & $\begin{array}{l}\text { Blocks synthesis of } \\
\text { adenine and guanine: } \\
\text { ARR reduction from } 2.20 \\
\text { to } 0.52 \text { over a median } \\
\text { duration of } 22 \text { months in } \\
99 \text { patients. }\end{array}$ \\
\hline $\begin{array}{l}\text { Mycophenolate } \\
\text { mofetil (+ } \\
\text { prednisone) (PO) }\end{array}$ & $\begin{array}{l}\text { 1000-3000 mg/day }(+30 \\
\mathrm{mg} / \text { day): Two daily doses } \\
\text { (prednisone taper after 6- } \\
9 \text { months) }\end{array}$ & $\begin{array}{l}\text { Consider target of absolute } \\
\text { lymphocyte count of } 1.0- \\
1.5 \mathrm{k} / \mu \mathrm{L} ; \text { monthly liver } \\
\text { function tests for first } 6 \\
\text { months, then quarterly }\end{array}$ & $\begin{array}{l}\text { If ALC goal cannot be } \\
\text { reached at maximum dose } \\
\text { of } 3000 \mathrm{mg} \text { /day, observe } \\
\text { closely for relapse. Switch } \\
\text { to rituximab } \\
\text { Check trough levels of } \\
\text { metabolite. }\end{array}$ & $\begin{array}{l}\text { Inhibits inosine } \\
\text { monophosphate } \\
\text { dehydrogenase, primarily } \\
\text { the type II isoform found } \\
\text { in T cells and B cells: } \\
\text { ARR reduction from } 1.28 \\
\text { to } 0.09 \text { over a median } \\
\text { follow-up of } 28 \text { months in } \\
24 \text { patients }\end{array}$ \\
\hline Rituximab & $\begin{array}{l}1000 \mathrm{mg} \text { IV for adults; } \\
\text { Two doses of } 1000 \mathrm{mg} 14 \\
\text { days apart. } \\
375 \mathrm{mg} / \mathrm{m}^{2} \text { for children } \\
\text { for four weekly doses of } \\
375 \mathrm{mg} / \mathrm{m}^{2}\end{array}$ & $\begin{array}{l}\text { Monthly CD19+ B cells } \\
\text { starting immediately } \\
\text { postinfusion; if CD } 19^{+} \\
\text {count exceeds } 1 \% \text { of total } \\
\text { lymphocytes, re-dose with } \\
\text { rituximab. If suppression } \\
\text { of CD } 19^{+} \text {count does not } \\
\text { occur, consider switching } \\
\text { to alternative. Monitor } \\
\text { immunoglobulins yearly. }\end{array}$ & $\begin{array}{l}\text { Relapses during first } 3 \\
\text { weeks of initial dosing are } \\
\text { not failures. Relapses when } \\
\text { CD19 } 19^{+} \text {count is greater than } \\
1 \% \text { are failures due to } \\
\text { undertreatment. Switch to } \\
\text { azathioprine or } \\
\text { mycophenolate mofetil. }\end{array}$ & $\begin{array}{l}\text { Anti-CD20, B cell } \\
\text { depletion: ARR from } 1.7 \\
\text { to } 0 \text { after a median follow- } \\
\text { up of } 19 \text { months in } 25 \\
\text { patients. }\end{array}$ \\
\hline Prednisone (PO) & $\begin{array}{l}\text { 15-30 mg: Daily dose; } \\
\text { taper after } 1 \text { year }\end{array}$ & $\begin{array}{l}\text { Monitor for } \\
\text { hyperglycemia, blood } \\
\text { pressure; DEXA scans as } \\
\text { appropriate for } \\
\text { osteoporosis; vitamin D } \\
\text { and calcium } \\
\text { supplementation as } \\
\text { needed; consider proton } \\
\text { pump inhibitors for gastric } \\
\text { protection }\end{array}$ & $\begin{array}{l}\text { Prednisone monotherapy } \\
\text { not recommended for long- } \\
\text { term use beyond } 1.5 \text { years. } \\
\text { Switch to azathioprine, } \\
\text { mycophenolate, or } \\
\text { rituximab. }\end{array}$ & Multiple effects \\
\hline Methotrexate (PO) & 15-25 mg weekly & $\begin{array}{l}\text { Check for liver toxicity } \\
\text { every } 3 \text { months; } \\
\text { recommend folate } 1 \mathrm{mg} \\
\text { supplementation; avoid } \\
\text { non-steroidal anti- } \\
\text { inflammatory drugs. }\end{array}$ & $\begin{array}{l}\text { Switch to azathioprine, } \\
\text { mycophenolate mofetil, or } \\
\text { rituximab. }\end{array}$ & Folic acid antagonist \\
\hline Mitoxantrone (IV) & $\begin{array}{l}12 \mathrm{mg} / \mathrm{m}^{2} \text { monthly } \times 6 \text {, } \\
\text { followed by monthly } \\
\text { maintenance dose of } 6 \\
\mathrm{mg} / \mathrm{m}^{2} \text {. Total cumulative } \\
\text { dose no greater than } 120 \\
\mathrm{mg} / \mathrm{m}^{2} \text {. }\end{array}$ & $\begin{array}{l}\text { Baseline and monthly } \\
\text { echocardiogram to exclude } \\
\text { patients and discontinue } \\
\text { drug if left ventricular } \\
\text { ejection fraction }<50 \% \text {. }\end{array}$ & $\begin{array}{l}\text { For consideration, with } \\
\text { caution, after exhausting } \\
\text { first-line options. The } \\
\text { maximum cumulative dose } \\
\text { is } 120 \mathrm{mg} / \mathrm{cm}^{2} \text {. Switch to } \\
\text { azathioprine, } \\
\text { mycophenolate mofetil, or } \\
\text { rituximab }\end{array}$ & $\begin{array}{l}\text { Intercalates DNA, inhibits } \\
\text { mitosis: ARR reduced } \\
\text { from } 2.8 \text { to } 0.7 \text { over a } \\
\text { median follow up of } 17 \\
\text { months in } 20 \text { patients }\end{array}$ \\
\hline Cyclophosphamide & \multicolumn{3}{|c|}{ Generally not standard of care } & Inhibits mitosis \\
\hline Cyclosporin A & \multicolumn{3}{|c|}{ Generally not standard of care } & Inhibits T cells \\
\hline
\end{tabular}

